\title{
AS ESCADARIAS DE TERRAÇOS DO RÓDÃO À CHAMUSCA (BAIXO TEJO) - CARACTERIZAÇÃO E INTERPRETAÇÃO DE DADOS SEDIMENTARES, TECTÓNICOS, CLIMÁTICOS E DO PALEOLÍTICO
}

\author{
PEDRO PROENÇA CUNHA ${ }^{(1)}$, ANTÓNIO A. MARTINS ${ }^{(2)}$ \& MARGARIDA PORTO GOUVEIA ${ }^{(3)}$
}

Resumo:

Abstract:

\begin{abstract}
As unidades estratigráficas que resultaram da evolução do rio Tejo em Portugal, aqui analisadas em pormenor entre Vila Velha de Ródão e Chamusca, possuem distintas características sedimentares e indústrias líticas: uma unidade culminante do enchimento sedimentar (o ancestral Tejo, antes do início da etapa de incisão fluvial) - SLD13 (+142 a $262 \mathrm{~m}$ acima do leito actual; com provável idade 3,6 a 1,8 Ma), sem indústrias identificadas; terraço T1 (+76 a $180 \mathrm{~m}$; ca. 1000 ? a $900 \mathrm{ka})$, sem indústrias; terraço T2 (+57 a $150 \mathrm{~m}$; idade estimada em ca. $600 \mathrm{ka})$, sem indústrias; terraço T3 (+36 a $113 \mathrm{~m}$; ca. 460 a 360 ? ka), sem indústrias; terraço T4 (+26 a $55 \mathrm{~m}$; ca. 335 a $155 \mathrm{ka}$ ), Paleolítico Inferior (Acheulense) em níveis da base e intermédios mas Paleolítico Médio inicial em níveis do topo; terraço T5 ( +5 a $34 \mathrm{~m}$; 135 a 73 ka), Paleolítico Médio (com talhe Mustierense, Levallois); terraço T6 (+3 a 14 m; 62 a 32 ka), Paleolítico Médio final (Mustierense final); Areias da Carregueira (areias eólicas) e coluviões (+3 a ca. $100 \mathrm{~m}$; 32 a $12 \mathrm{ka}$ ), Paleolítico Superior a Epipaleolítico; enchimento da planície aluvial ( +0 a $8 \mathrm{~m}$; ca. $12 \mathrm{ka}$ a actual), Mesolítico e indústrias mais recentes. As diferenças na elevação (a.r.b.) das escadarias de terraços resultam de soerguimento diferencial, devido a falhas ativas. Numa dada escadaria datada, a projeção da elevação da superfície de cada terraço (a.r.b.) versus a sua idade permitiu estimar a idade do topo do terraço T2 (ca. $600 \mathrm{ka}$ ) e a provável idade do início da etapa de incisão (ca. 1,8 Ma). Obteve-se a duração da fase de agradação dos terraços baixos e médios: T6 - $30 \mathrm{ka}$; T5 $62 \mathrm{ka}$ T 4 - ca. $180 \mathrm{ka}$ T3 - ca. 100? ka. Conclui-se que durante o Plistocénico médio e final, as fases de incisão e alargamento do vale foram curtas (ca. 11-25 ka) e ocorreram durante períodos de nível do mar muito baixo, alternando com mais longas fases de inundação e agradação do vale durante níveis do mar mais altos. Estas oscilações eustáticas de causa climática estão sobrepostas a um contexto de soerguimento de longo termo, controlando o desenvolvimento das escadarias. Calculou-se que para os últimos ca. $155 \mathrm{ka}$ as taxas de incisão de curto-termo apresentam valores $(0,09$ a $0,41 \mathrm{~m} / \mathrm{ka}$ ), aproximadamente, duplos dos calculados para o intervalo ca. 155 a $900 \mathrm{ka}(0,04 \mathrm{a} 0,28 \mathrm{~m} / \mathrm{ka})$. Este aumento na taxa de incisão deve estar relacionado com um aumento na taxa de soerguimento por intensificação da compressão devido à convergência entre as placas Africana e Eurasiática.
\end{abstract}

Palavras-chave: terraços fluviais, tectónica, taxa de incisão, levantamento tectónico, rio Tejo, Portugal.

The terrace staircases of the Lower Tagus River (Ródão to Chamusca) - characterization and interpretation of the sedimentary, tectonic, climatic and Palaeolithic data

The stratigraphic units that record the evolution of the Tagus River in Portugal (study area between Vila Velha de Ródão and Chamusca villages) have different sedimentary characteristics and lithic industries: a culminant sedimentary unit (the ancestral Tagus, before the drainage network entrenchment) - SLD13 (+142 to $262 \mathrm{~m}$ above river bed - a.r.b.; with probable age 3.6 to $1.8 \mathrm{Ma}$ ), without artefacts; T1 terrace (+76 to $180 \mathrm{~m}$; ca. 1000 ? to $900 \mathrm{ka})$, without artefacts; T2 terrace ( +57 to $150 \mathrm{~m}$; top deposits with a probable age ca. $600 \mathrm{ka})$, without artefacts; T3 terrace ( +36 to $113 \mathrm{~m}$; ca. 460 to 360 ? ka), without artefacts; T4 terrace ( +26 to $55 \mathrm{~m}$; ca. 335 a $155 \mathrm{ka}$ ), Lower Paleolithic (Acheulian) at basal and middle levels but early Middle Paleolithic at top levels; T5 terrace ( +5 to $34 \mathrm{~m} ; 135$ to $73 \mathrm{ka}$ ), Middle Paleolithic (Mousterian; Levallois technique); T6 terrace ( +3 to $14 \mathrm{~m} ; 62$ to $32 \mathrm{ka}$ ), late Middle Paleolithic (late Mousterian); Carregueira Sands (aeolian sands) and colluvium ( +3 a ca. $100 \mathrm{~m} ; 32$ to $12 \mathrm{ka}$ ), Upper Paleolithic to Epipaleolithic; alluvial plain ( +0 to $8 \mathrm{~m}$; ca. $12 \mathrm{ka}$ to present), Mesolithic and more recent industries. The differences in elevation (a.r.b.) of the several terrace staircases results from differential uplift due to active faults. The age interval for each aggradation phase of T3 to T6 terraces was obtained: T3 - ca. 100 ? ka; T4 - ca. $180 \mathrm{ka}$; T5 - 62 ka; T6 - 30 $\mathrm{ka}$. The intervals of river down-cutting and widening of the valley floor were short (ca. 11-25 ka) and coincided with periods of very low sea-level. The plotting of the elevation (a.r.b.) versus the age of each terrace surface allows to estimate the age of the T2 terrace (ca. $600 \mathrm{ka}$ ) and the probable age of the beginning of the incision stage (ca. $1.8 \mathrm{Ma}$ ). So, the high amplitude sea-level changes that characterized the Middle and Late Pleistocene strongly determined the episodic down-cutting phases of the river during the low stands sea levels that alternated with the flooding and aggradation phases of the incised valley during highstand sea levels. These climate related eustatic oscillations are superimposed onto a long term uplift pattern, controlling the river terrace staircase development. During the last ca. $155 \mathrm{ka}$, the short-term incision rates $(0.09 \mathrm{a} 0.41 \mathrm{~m} / \mathrm{ka})$ were twice the values determined for the interval 155 to $900 \mathrm{ka}$ $(0.04$ to $0.28 \mathrm{~m} / \mathrm{ka})$. This increase in incision rate should be related with an increase in uplift rate resulting from an intensification of compression due to the convergence between African - Eurasian plates.

Keywords: fluvial terrace, tectonics, incision rate, uplift, Tagus River, Portugal.

Received: 28 April, 2016; Accepted: 6 May, 2016

(1) MARE - Centro de Ciências do Mar e do Ambiente; Departamento de Ciências da Terra da Universidade de Coimbra; Rua Sílvio Lima, Univ. Coimbra - Pólo II; 3030-790 Coimbra; pcunha@dct.uc.pt; mariamporto@gmail.com

${ }^{(2)}$ Instituto de Ciências da Terra (ICT), Departamento de Geociências, Universidade de Évora, Rua Romão Ramalho, 59, 7000-671 Évora; aam@uevora.pt 


\section{INTRODUÇÃO}

Os registos sedimentares presentes nas escadarias de terraços fluviais são valiosos arquivos do passado em áreas terrestres, fornecendo informações sobre as condições sedimentares e hidrodinâmicas de antigas drenagens e da sua evolução, variações climáticas e ocupação humana (e.g. DAVEAU 1980, 1993; BRIDGLAND \& MADDY 2000; BRIDGLAND et al. 2006; BRIDGLAND \& WESTAWAY 2008; SANTONJA \& PÉREZ-GonZÁlez 2010). Por outro lado, constituem importantes referências geomórficas que permitem determinar as taxas de incisão dos rios (e.g. HANCOK \& ANDERSON 2002; PEDERSON et al. 2006), bem como identificar soerguimento diferencial e as falhas ativas associadas.

As escadarias de terraços fluviais formam-se num contexto de soerguimento tectónico regional em que os controlos que se exercem sobre a dinâmica fluvial determinam uma alternância de ciclos que envolvem fases de incisão (predomina o escavamento vertical), de alargamento do vale (equilíbrio dinâmico, só existe erosão lateral que promove o alargamento do vale) e de agradação (predomina a deposição de sedimentos) (e.g. BULL 1990; Pederson et al. 2006). Neste contexto, as fases de incisão geralmente predominam, pelo que, no longo prazo, ocorre um progressivo encaixe da rede hidrográfica. Por isso, quando o mecanismo forçador da incisão fluvial é a tectónica regional, as taxas de incisão fluvial podem ser usadas como equivalentes, aproximados, das taxas de levantamento tectónico (MADDY et al. 2000).

$\mathrm{O}$ rio Tejo tem acentuada sazonalidade e variabilidade anual de caudal, apresentando pontas de cheia com mais de 30 vezes o caudal médio $(\sim 394$ $\mathrm{m}^{3} / \mathrm{s}$ ). É o mais longo curso de água da Península Ibérica, apresentando uma bacia hidrográfica de $81.947 \mathrm{~km}^{2}$ (BENITO et al. 2003). Cerca de 70\% desta área está situada em Espanha (vulgarmente designada por Alto Tejo) e 30\% em Portugal (designada por Baixo Tejo); aqui o rio tem $230 \mathrm{~km}$ de comprimento e um declive médio de $0,03 \%$.

A localização estratégica do rio Tejo, atravessando grande parte da Península Ibérica e desaguando no Oceano Atlântico (Figs. 1 e 2), bem como o grande desenvolvimento espacial e espessura dos seus terraços, determinam que este constitua um relevante arquivo continental e mesmo um "laboratório natural" que permite avaliar o papel dos mecanismos forçadores da evolução fluvial (tectónica, eustatismo e clima) e compreender as transformações paleogeográficas que ocorreram nos cerca de 4 milhões de anos de evolução deste rio atlântico.

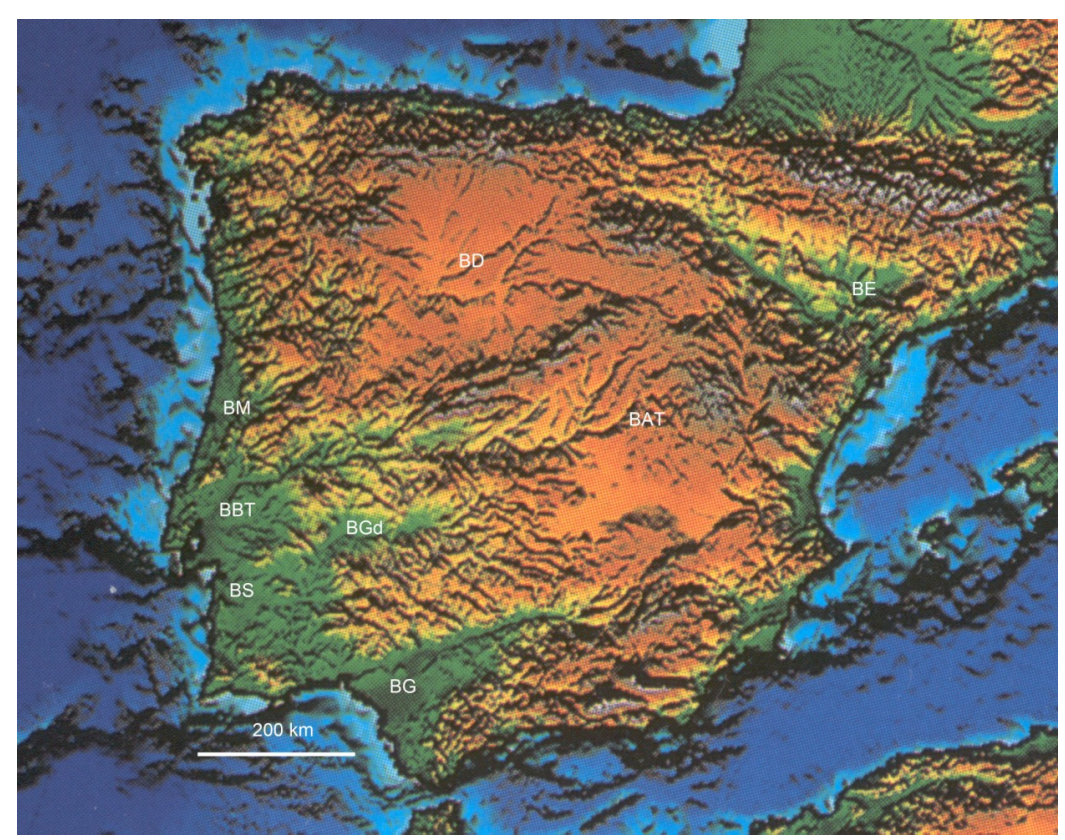

Fig. 1. Modelo digital da Península Ibéria (MDT) e áreas marinhas adjacentes, onde se distinguem bem as bacias com drenagem atlântica (a cor verde) que capturaram a drenagem de bacias cenozoicas endorreicas (a cor laranja) do interior da Ibéria (e.g. bacias cenozoicas do Douro e de Madrid). Principais bacias cenozoicas: BM - Bacia do Mondego; BBT - Bacia do Baixo Tejo; BS - Bacia do Sado; BGd - Bacia do Guadiana; BG - Bacia do Guadalquivir; BD - Bacia do Douro; BAT - Bacia do Médio e Alto Tejo (Madrid); BE - Bacia do Ebro.

Fig. 1. Digital Elevation Model (MDT) of the Iberian Peninsula and adjacent marine areas, showing the Atlantic Cenozoic basins (green color) which captured the drainage of the endorheic Douro and Upper-Middle Tagus Cenozoic basins (orange color). Main Cenozoic basins: BM - Mondego basin; BBT - Lower Tagus basin; BS - Sado basin; BGd - Guadiana basin; BG - Guadalquivir basin; BD - Douro basin; BAT - Upper Tagus (Madrid) basin; BE - Ebro basin. 


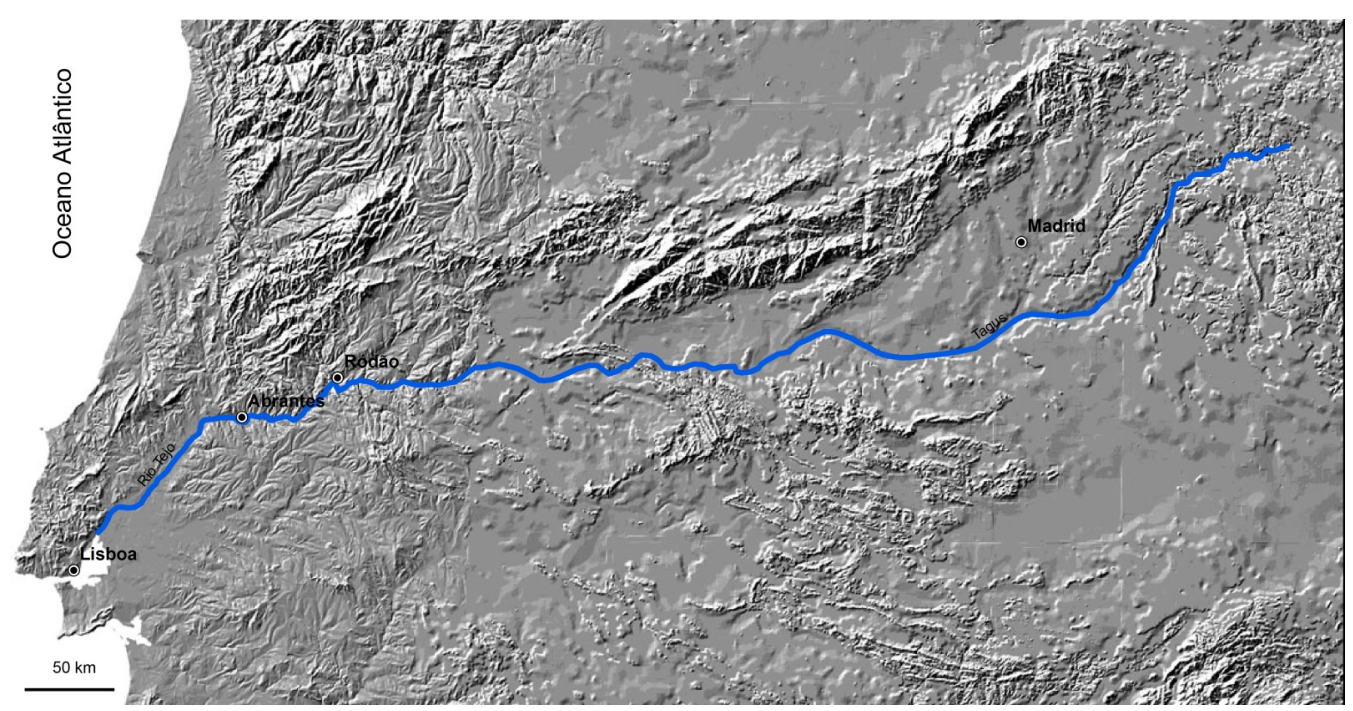

Fig. 2. Modelo digital de terreno (dados altimétricos do SRTM v4) da região atravessada pelo rio Tejo, na Península Ibérica, até à foz no Oceano Atlântico $(1.076 \mathrm{~km})$. De leste para oeste, distingue-se o Alto Tejo e o Médio Tejo no relevo quase plano na Bacia Cenozoica de Madrid, depois a estreita zona de transição onde o Tejo corre em vale encaixado ca. $200 \mathrm{~m}$ no soco metamórfico e granitoide, bem como o sector a jusante que apresenta a rede hidrográfica essencialmente desenvolvida na Bacia Cenozoica do Baixo Tejo e com traçado controlado por lineamentos tectónicos (E-W e NE-SW). Fig. 2. Digital Elevation Model (altimetry from SRTM v4) of the region crossed by the Tagus River, in the Iberian Peninsula, until the river mouth in the Atlantic Ocean $(1,076 \mathrm{~km})$. From east to west, the river crosses the low relief landscape of the Madrid Cenozoic basin (the High-Middle Tagus drainage basin), the narrow transition area in which the river is $200 \mathrm{~m}$ incised in the metamorphic and granitic basement, and the downstream sector along the Lower Tagus Cenozoic basin, where the river seems to be controlled by tectonic lineaments (E-W and NE-SW).

Durante os últimos trinta anos, essencialmente a partir de Costa (1984) e Martins (1999), fez-se uma pormenorizada caracterização das escadarias de terraço associadas ao rio Tejo em Portugal, sector da bacia hidrográfica habitualmente designado por Baixo Tejo (e.g. síntese por CUNHA et al. 2012), e similar desenvolvimento se verificou no sector da bacia localizada em Espanha, designada por Alto e Médio Tejo (ou por Bacia de Madrid) (e.g. MARTín-SERRANO 1991; PÉREZ-GonZÁleZ 1994; MARTín et al. 1995; PÉREZ-GONZÁLEZ et al. 2004; ROQUERO et al. 2015a,b).

Até 2008 apenas existiam publicadas 12 idades numéricas dos terraços no Baixo Tejo, sendo de terraços recentes (RAPOSO 1995a; RAPOSO \& CARDOSO 1998): 4 por séries de Urânio e 8 por termoluminescência (TL), no intervalo ca. $27 \mathrm{ka}$ a $>130 \mathrm{ka}$ (as mais antigas, eram apenas idades mínimas, por limitações do método usado). Na última década, o ritmo na obtenção de idades acelerou-se, principalmente por luminescência opticamente estimulada (OSL) (ALMEIDA et al. 2008; CUNHA et al. 2008a, 2012; MARTINS et al. 2009a,b, 2010a,b). Idêntica situação ocorreu na Bacia do Alto Tejo em que se obtiveram idades absolutas em terraços com superfícies situadas até ca. de $+40 \mathrm{~m}$ acima do leito (a.r.b.) no rio Henares (BENITO CALVO et al. 1998; ORTíz et al. 2005), Jarama (PANERA et al. 2011; PÉREZ-GONZÁlez et al. 2013), rio Manzanares (PÉREZ-GONZÁlEZ et al. 2008; SILVA et al. 2013a; LÓPEZ RECIO et al. 2015) e rio Tejo (RoQUERO et al. 2015a,b; LÓPEZ RECIO et al. 2015).
Os avanços na caracterização das escadarias de terraços e, em particular da sua datação, permitem uma melhor reconstituição do contexto paleogeográfico, climático e tectónico, bem como do posicionamento temporal das indústrias paleolíticas associadas. A datação também determina as durações das fases de agradação e de incisão/ alargamento do vale associadas com os terraços, permitindo interpretar o papel desempenhado pelos controlos fluviais alocíclicos (clima, glacioeustatismo e tectónica).

Este trabalho incide nos registos sedimentares do vale do Tejo, situados entre Vila Velha de Ródão e Chamusca; pretende propor um modelo genético aplicável ao Baixo Tejo, de relevância na interpretação da evolução desta região do oeste ibérico durante o Quaternário.

\section{GEOLOGIA E GEOMORFOLOGIA DA BACIA CENOZOICA DO BAIXO TEJO}

A área de estudo situa-se na Bacia Cenozoica do Baixo Tejo (BCBT). Nesta, o relevo é dominado por um planalto correspondente à superfície culminante do enchimento sedimentar (CSS), decrescendo em altitude desde ca. 350-290 m (Vila Velha de Ródão) a ca. 80-65 m (no eixo deprimido da Península de Setúbal, mas elevando-se para a Serra da Arrábida) (Figs. 2, 3 e 4). Abaixo desta superfície de agradação desenvolvem-se escadarias de terraços fluviais, que já se inserem na etapa de encaixe da rede hidrográfica. 


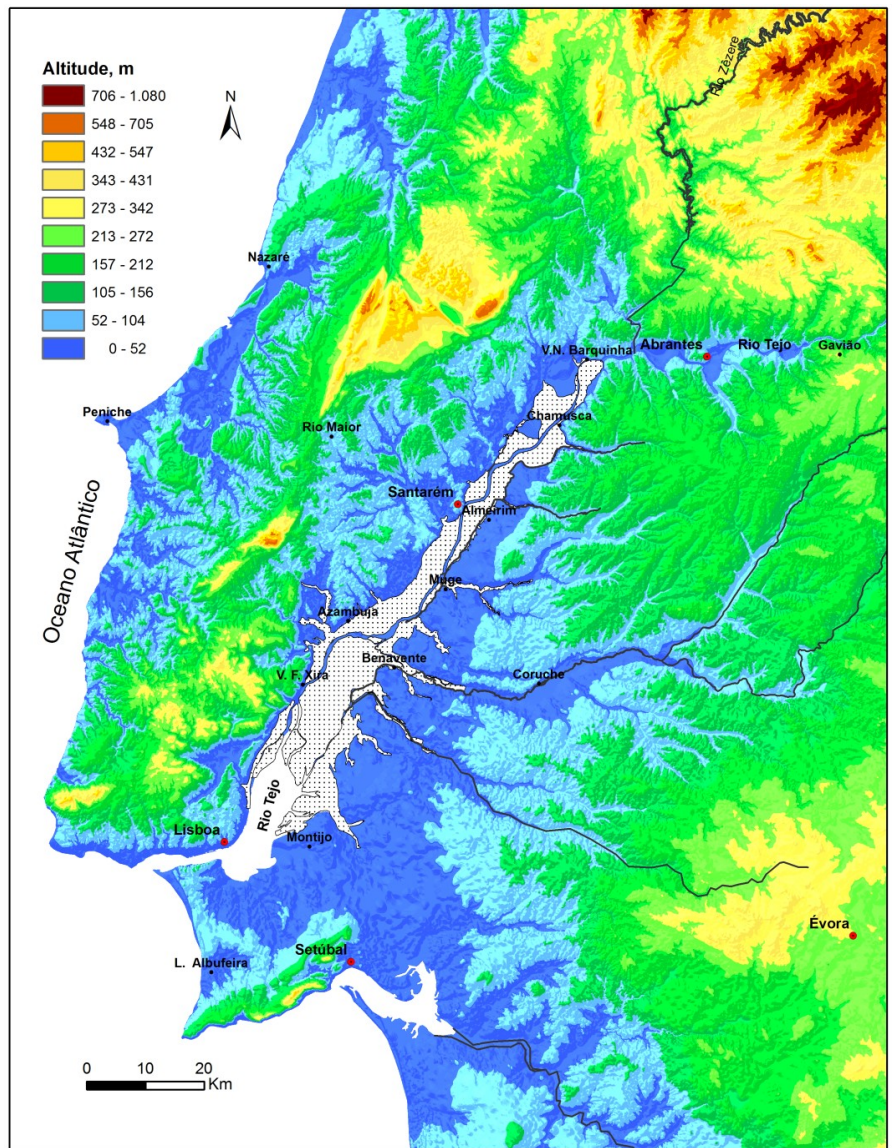

Fig. 3. Hipsometria do Baixo Tejo, identificando-se o rio Tejo e os seus principais afluentes (modelo digital de terreno baseado nos dados altimétricos ASTER, com $30 \mathrm{~m}$ de píxel).

Fig. 3. Hipsometry of the Lower Tagus basin; the Tagus River (Rio Tejo) and main tributaries are identified (digital elevation model provided by ASTER altimetry data, $30 \mathrm{~m}$ pixel).

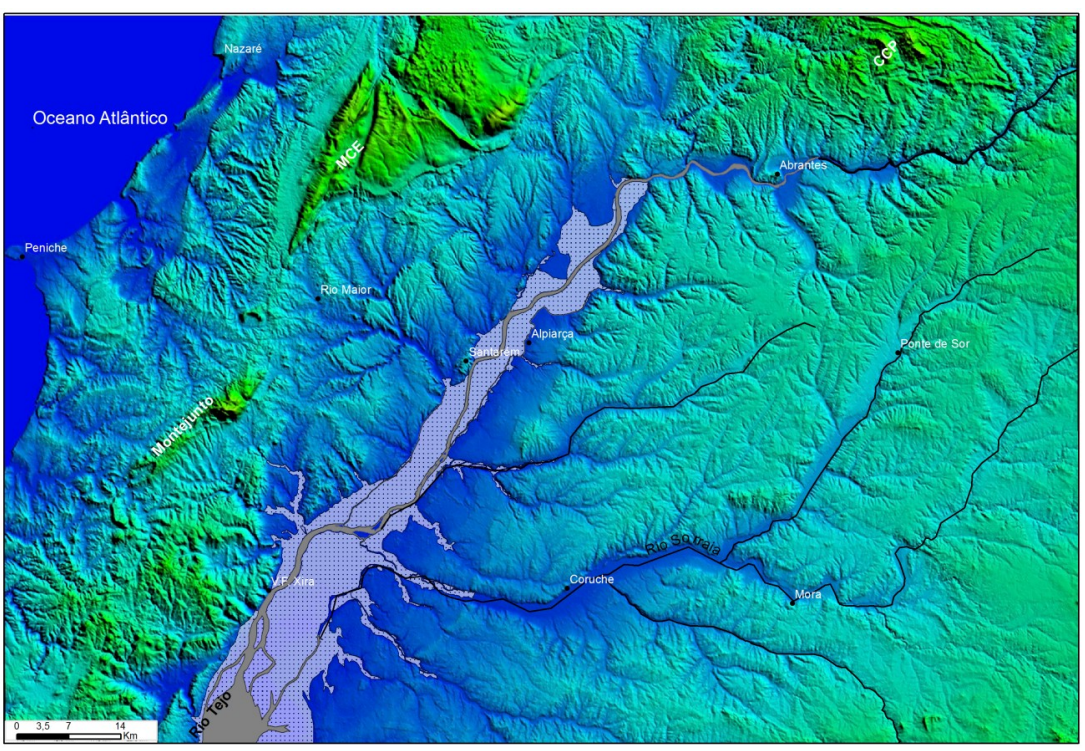

Fig. 4. Pormenor do relevo nos sectores centrais da Bacia hidrográfica do Baixo Tejo (modelo digital de terreno baseado nos dados altimétricos ASTER, com $30 \mathrm{~m}$ de píxel). MCE - Maciço Calcário Estremenho; CCP - Cordilheira Central Portuguesa.

Fig. 4. The relief of the central part of the Lower Tagus drainage basin (digital elevation model provided ASTER altimetry data, $30 \mathrm{~m}$ pixel). MCE - Estremenho Limestone Massif; CCP - Portuguese Central Cordillera. 
O primeiro estudo geológico abrangendo a quase totalidade da Bacia Cenozoica do Baixo Tejo foi o de Carvalho (1968) que, embora não tenha incidido "no registo sedimentar do Quaternário médio e recente", evidenciou as deformações tectónicas pós-pliocénicas. Após avanços resultantes de várias teses de doutoramento que incidiram no enchimento sedimentar desta bacia (e.g. PAIS 1981; AZEVEDO 1982; CUNHA 1992a; BARBOSA 1995; MARTINS 1999; LEGOINHA 2001), as mais recentes sínteses à escala da bacia são as de Pais et al. (2012, 2013); o enquadramento tectónico foi atualizado por De Vicente et al. (2011).

A região apresenta um soco metamórfico e magmático, do Paleozoico e Pré-Câmbrico, resistente à erosão, bem como rochas sedimentares calcárias e siliciclásticas do Mesozoico (Fig. 5). O enchimento da bacia cenozoica é dominado por sedimentos do Miocénico no sector ocidental e sedimentos do Pliocénico a Plistocénico inferior nos sectores norte e oriental. O Paleogénico é constituído por sedimentos aluviais areno-cascalhentos arcósicos. O Miocénico compreende arcoses, siltes argilosos e calcários lacustres/palustres. A unidade alostratigráfica culminante do enchimento (SLD13; CUNHA 1992a,b) compreende fácies de leques aluviais, fluviais e deltaicas, com provável idade do final do Zancliano ao Plistocénico inicial (3,6 Ma a ca. 1,8 Ma; CUNHA et al. 1993, 2012; PAIS et al. 2012). Este intervalo resulta da: a) biostratigrafia combinando nanofósseis calcários e gastrópodes, e por datação de conchas de pectinídeos $\left({ }^{87} \mathrm{Sr} /{ }^{86} \mathrm{Sr}\right)$ de depósitos da base em Vale do Freixo (Bacia Cenozoica do Mondego; CACHÃO 1990; SILVA 2001); b) pela identificação da passagem Gauss-Matuyama (2,58 Ma) em nível ca. de $17 \mathrm{~m}$ abaixo do topo da unidade (SLD13) em Rio Maior (Bacia Cenozoica do Baixo Tejo) (DINIZ \& MÖRNER 1995); c) idade do topo da SLD13 obtida por extrapolação, a partir da função elevação (a.r.b.)/idade dos níveis de terraço datados na Bacia do Baixo Tejo (CunHA et al. 2012).

Os sedimentos plistocénicos estão representados por depósitos de terraços, coluviões e uma unidade eólica de cobertura (Areias da Carregueira) (e.g. MARTINS et al. 2009a,b, 2010a,b; CUNHA et al. 2012). Os sedimentos holocénicos constituem uma planície aluvial que atinge ca. $10 \mathrm{~km}$ de largura e preenchem o vale que foi escavado na descida do nível do mar durante o Estágio Isotópico Marinho (MIS) 2, entre 30.000 e 20.000 anos BP (e.g. DAVEAU \& GONÇALVES 1985; VAN DER SCHRIEK et al. 2007; VIS et al. 2008, 2016; VIS 2009). Os materiais do Neogénico constituíram a principal fonte de sedimentos para os depósitos de terraços plistocénicos.

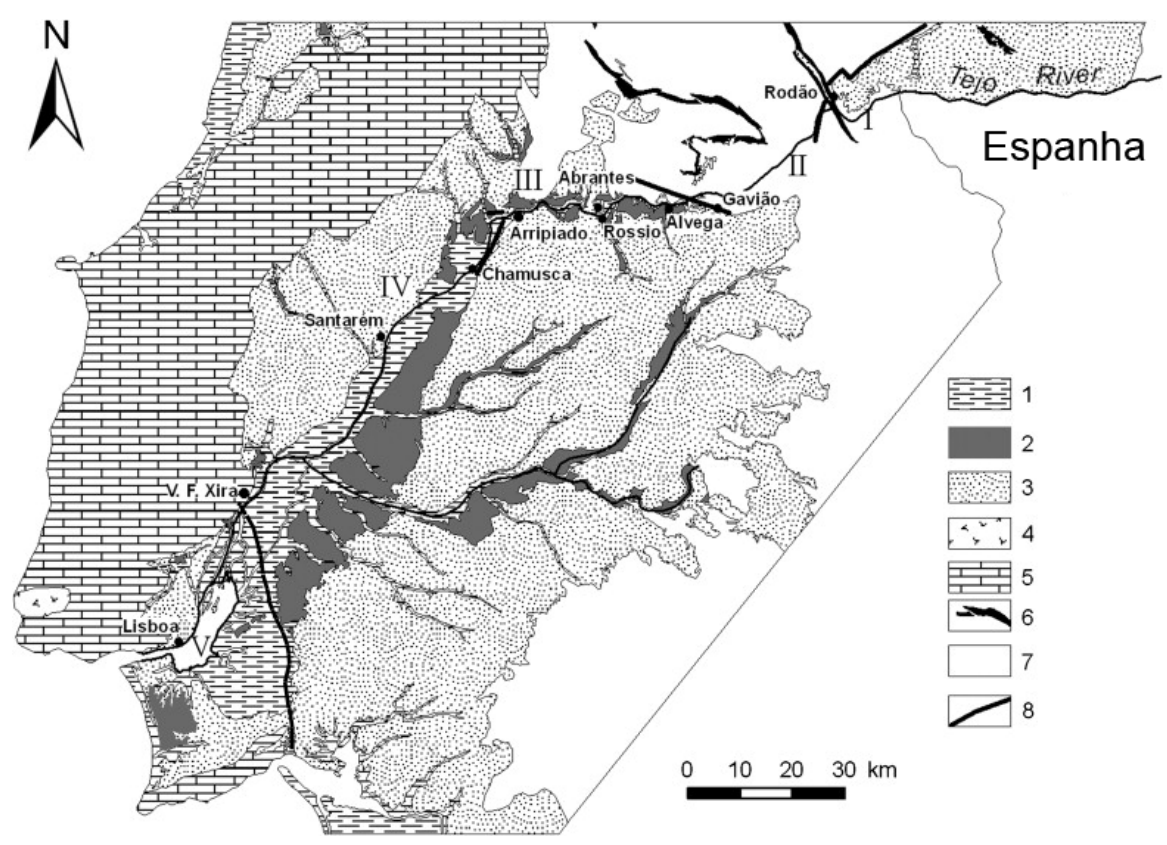

Fig. 5. Mapa geológico simplificado da Bacia Cenozoica do Baixo Tejo (adaptado da Carta Geológica de Portugal na escala 1/500000, de 1992). 1 - aluviões (Holocénico); 2 - terraços (Plistocénico); 3 arenitos e conglomerados (Paleogénico a Pliocénico); 4 - Maciço ígneo de Sintra (Cretácico); 5 calcários, margas, siltes e arenitos (Mesozoico); 6 - quartzitos (Ordovícico); 7 - soco indiferenciado (Paleozoico); 8 - falhas. Estão representados os principais troços do rio Tejo em Portugal (I a V).

Fig. 5. Simplified geologic map of the Lower Tagus Cenozoic basin, adapted from the Carta Geológica de Portugal, 1/500,000, 1992). 1 - alluvium (Holocene); 2 - terraces (Pleistocene); 3 - sandstones and conglomerates (Paleogene to Pliocene); 4 - Sintra Massif (Cretaceous); 5 - limestones, marls, silts and sandstones (Mesozoic); 6 - quartzites (Ordovician); 7 - basement (Paleozoic); 8 - faults. The main Portuguese reaches of the Tagus River are identified (I to V). 
No Baixo Tejo, Cunha et al. (2005) subdividiu o vale do rio Tejo em cinco troços principais (I a V), separados por falhas importantes (Figs. 5 e 6): I - do Tejo Internacional ao Arneiro (Ródão), troço com terraços e limitado a jusante pela falha do Ponsul-Arneiro; II - da falha do Ponsul - Arneiro à zona de falha do Gavião, troço NE-SW escavado no soco, apenas com terraços de rocha vestigiais; III - da zona de falha do Gavião ao cruzamento da falha de Vila Nova da Barquinha (W-E) com a falha do Arripiado-Chamusca (NNE-SSW), troço E
-W com escadarias de terraços em alvéolos tectónicos (respetivamente, os de Alvega, Rossio, Tramagal e Tancos); IV - do Arripiado às falhas do Pinhal Novo-Vila Franca de Xira, troço NNE-SSW correspondente à zona de falha do Vale Inferior do Tejo e apresentando escadarias de terraços bem desenvolvidas e uma larga planície aluvial; V - de Vila Franca de Xira até à foz no Oceano Atlântico, troço correspondente ao estuário, com menor soerguimento e orientado NNE-SSW a E-W.

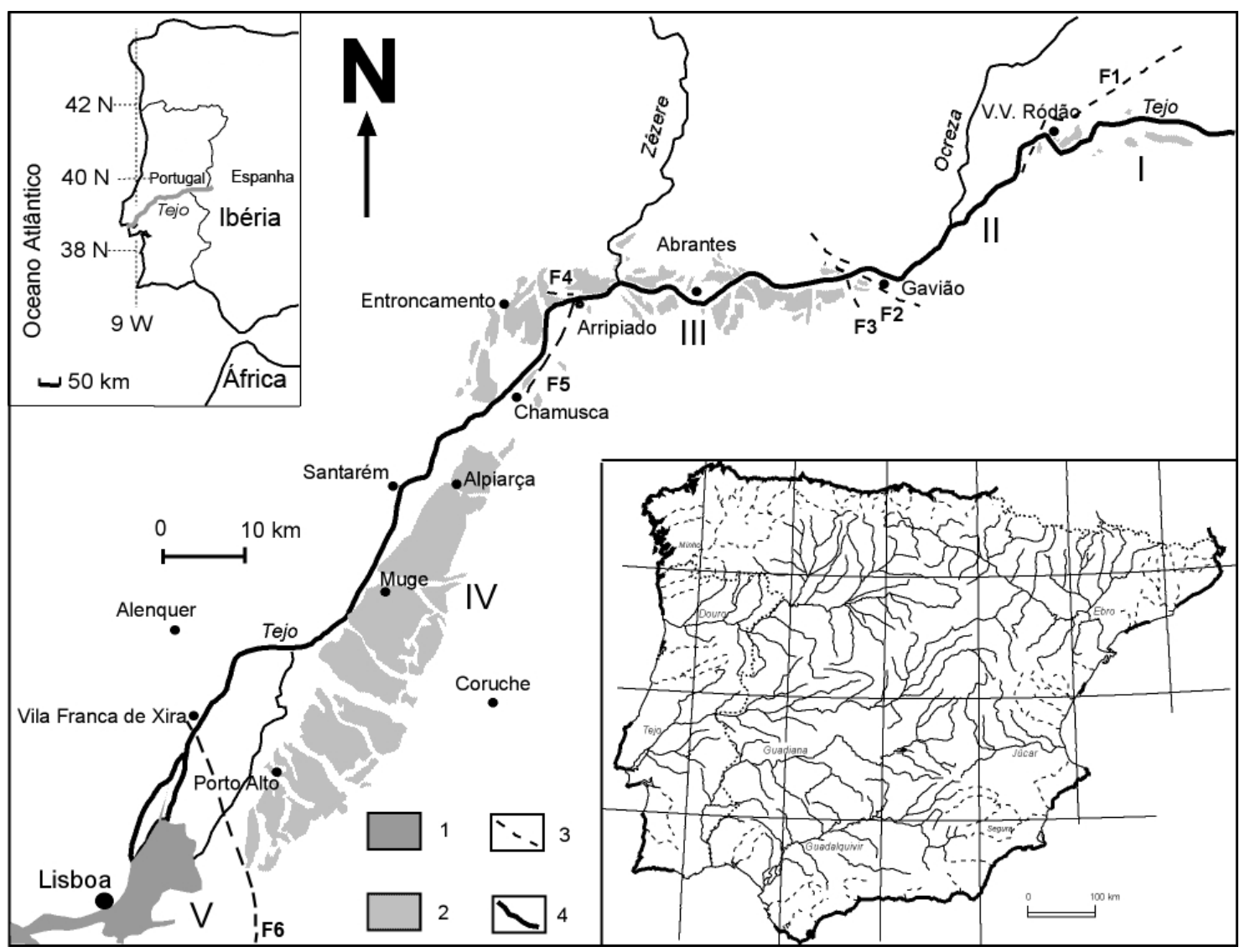

Fig. 6. Principais troços do rio Tejo em Portugal (Bacia do Baixo Tejo): I - da fronteira ao Arneiro (depressões de Ródão e Arneiro; um traçado geral E-W constituído, principalmente, de segmentos poligonais); II - do Arneiro ao Gavião (NE-SW); III - do Gavião ao Arripiado (E-W); IV - do Arripiado a Vila Franca de Xira (NNE-SSW); V - de Vila Franca de Xira ao litoral Atlântico. Representam-se as falhas que delimitam os diferentes troços: F1 - falha do Ponsul-Arneiro (WSW-ENE); F2 - falha do Gavião (NW-SE); F3 - falha de Ortiga (NW-SE); F4 - falha de Vila Nova da Barquinha (W-E); F5 - falha do Arripiado-Chamusca (NNESSW); F6 - falhas do Pinhal Novo (N-S) -Vila Franca de Xira (NW-SE). 1 - estuário; 2 - terraços; 3 - falhas; 4 - canal principal do Tejo. Representam-se também as principais bacias de drenagem ibéricas (este inset modificado de Flor 1999).

Fig. 6. Main Portuguese reaches in which the Tejo River can be divided (Lower Tagus Basin): I - from the Spanish border to Arneiro (a general E-W trend, mainly consisting of polygonal segments); II - from Arneiro to Gavião (NE-SW); III - from Gavião to Arripiado (EW); IV - from Arripiado to Vila Franca de Xira (NNE-SSW); V - from Vila Franca de Xira to the Atlantic shoreline. The faults considered to be the limit of the referred fluvial sectors are represented: F1 - Ponsul-Arneiro fault (WSW-ENE); F2 - Gavião fault (NW-SE); F3 Ortiga fault (NW-SE); F4 - Vila Nova da Barquinha fault (W-E); F5 - Arripiado-Chamusca fault (NNE-SSW); F6 - Pinhal Novo fault (NS) -Vila Franca de Xira fault (NW-SE). 1 - estuary; 2 - terraces; 3 - faults; 4 - Tagus main channel. The main Iberian drainage basins are also represented (this inset modified from Flor 1999).

\section{ANTECEDENTES}

Os estudos de Breuil \& Zbyszewsky (1942, 1945) e Zbyszewski (1943, 1946, 1953, 1957) identificaram quatro níveis de terraço no Baixo Tejo. Foram representados nas cartas geológicas $1 / 50.000$ usando um critério baseado na elevação da superfície dos terraços acima do leito (a.r.b.): Q1 aos +75 a $95 \mathrm{~m}$; Q2 aos +50 a $65 \mathrm{~m}$; Q3 aos +25 a $40 \mathrm{~m}$ e Q4 aos +8 a $15 \mathrm{~m}$. Um modelo glácio-eustático, baseado nas glaciações alpinas, foi usado para explicar a 
formação dos terraços e indicar a sua cronologia relativa. O Q1 e o Q2, os "terraços superiores", foram relacionados com o interglacial GunzMindel, ou mesmo o pré-Gunz (Q1). O Q3, o "terraço médio", foi relacionado com o Mindel final a Riss inicial; o Q4, o "terraço inferior" foi atribuído ao interglacial Riss- Würm.

Estudos ulteriores, focalizados em determinados troços fluviais, estabeleceram seis níveis de terraço (T1 é o mais alto e o T6 o mais baixo; CORRAL 1998a,b; MARTINS 1999; ROSINA 2002; CUNHA et al. 2005, 2008a,b,c; MARTINS \& CUNHA 2009; MARTINS et al. 2009, 2010a,b,c). Os níveis adicionais foram reconhecidos na parte mais elevada e na mais baixa do vale, o novo nível mais elevado de terraço ocorrendo acima do nível Q1 e o novo nível mais baixo ocorrendo abaixo do Q4. Assim, a antiga estratigrafia compreendendo o Q1, Q2, Q3 e Q4 foi renomeada em T2, T3, T4 e T5.

A continuação de estudos geomorfológicos pormenorizados nos troços I, III e IV do Baixo Tejo, complementados com caracterizações sedimentológicas e datações absolutas, confirmaram a existência de um número máximo de seis níveis de terraço e documentaram o seu desenvolvimento espacial e temporal (CUNHA et al. 2012).

$\mathrm{Na}$ Bacia Cenozoica do Baixo Tejo existem evidências de falhas ativas e nela ocorreram sismos históricos. As principais dificuldades na identificação das estruturas sismogénicas resultam da sua lenta movimentação, originando escarpas em materiais cenozoicos que rapidamente se degradam, bem como pela sua cobertura por aluviões.

Já Choffat (1907) e Bensaúde (1910) admitiram que o vale inferior do Tejo estava instalado numa zona de fratura com orientação NNE-SSW. Freire de Andrade $(1933,1937)$ afirmou que “... o troço intermédio (entre o Carregado e o Terreiro do Paço) instalou-se ao longo de linhas de fratura com direção SW-NE”. Em Conde \& Santarém (1976), a falha do Vale Inferior do Tejo (VIT) é marcada com um traçado um tanto diferente da representada por Freire de Andrade e da sugerida por Choffat. Segundo o traçado proposto por Conde (1983), a zona de falha do VIT tem orientação $\mathrm{N} 30^{\circ} \mathrm{E}$ e comprimento de $125 \mathrm{~km}$, sendo constituída por duas falhas, continuando para além da plataforma continental, ao longo do vale submarino designado por canhão de Lisboa, por mais $20 \mathrm{~km}$.

No vale inferior do Tejo, merece destaque o sismo de 26 de janeiro de 1531, com magnitude 6.5 -7 e epicentro entre Vila Franca de Xira e Azambuja (JUSTO \& SALWA 1998), bem como o que a 22 de abril de 1909 destruiu a povoação de Benavente (Teves Costa \& BAtlló 2011). Foram identificadas como prováveis fontes deste último sismo a "falha do Tejo" (com traçado passando por Benavente) e a falha do Sorraia (BENSAÚDE 1910; DINIS 1910; CHOFFAT \& BENSAÚdE 1911; CHOFFAT 1912). Este sismo teve grande magnitude (MW =
6,0 to 6,2 ) (TeVes-Costa et al. 1999; Dineva et al. 2002; STICH et al. 2005; TEVES COSTA \& BATLLÓ 2011). Ulteriormente ocorreram alguns sismos com magnitude $\geq 4,0$ e cerca de duas dezenas com magnitude entre 3.0 e 3.9 (CARRILHO et al. 2004).

A zona de falha do Vale Inferior do Tejo tem tido estudos mais recentes (e.g. CABRAL et al. 1984, 2003a,b, 2004, 2008, 2011, 2013; CABRAL \& RIBEIRO 1989; CABRAL 1993; VILANOVA 2003; VILANOVA \& FONSECA 2004; CARVALHO et al. 2006, 2008; MARTINS et al. 2009a,b; BESANAOSTMAN et al. 2010, 2012).

No Vale Inferior do Tejo, identificaram-se os seguintes principais segmentos de falha activa, desnivelando a SLD13 e terraços mais antigos: falha de Vila Nova da Barquinha (E-W); falha do Arripiado-Chamusca (NNE-SSW); falha do Arrife (NE-SW); falha de Porto de Mós (NW-SE); falha de Santarém (NW-SE); falha de Rio Maior - Asseca (NW-SE); falha de Vila Franca de Xira (NNWSSE); falha de Ulme (E-W); falha da Azambuja (NNE-SSW); falha de Benavente (NNE-SSW); falha do Pinhal Novo-Alcochete (N-S a NNWSSE); falha do gargalo do Tejo (WSW-ENE); falha da Serra da Arrábida (WSW-ENE) (e.g. CONDE 1983; MARTINS 1999; CABRAL et al. 2003, 2004; VILANOVA \& FONSECA 2004; CARVALHO et al. 2014;). Outras falhas ativas já identificadas na Bacia do Baixo Tejo são a: falha do PonsulArneiro; falhas de Monte do Pinhal (NW-SE); falha do Gavião (NW-SE); falha de Ortiga (NW$\mathrm{SE}$ ); falha de Abrantes (E-W); falha do Crato (WNW-ESE); falha do Maranhão (WNW-ESE) (DIAS \& CABRAL 1989; MARTINS 1999; CUNHA et al. 2008a; MARTINS et al. 2009b).

\section{METODOLOGIAS}

A informação aqui sintetizada resulta do estudo dos registos sedimentares do rio Tejo, através das seguintes metodologias (e.g. STOKES et al. 2012): análise bibliográfica; estudo geomorfológico regional, complementado com levantamentos pormenorizados locais e da produção de mapas detalhados (geomorfológicos e MDT) usando ferramentas SIG; descrições de campo das unidades litostratigráficas e correlações das respetivas colunas estratigráficas; caracterização sedimentológica dos depósitos; datação absoluta.

\subsection{Geomorfologia}

A cartografia geomorfológica dos vários troços do vale do Baixo Tejo foi realizada em três etapas: (1) cartografia realizada no terreno, com base em mapas topográficos $(1 / 25.000)$ e geológicos (1/50.000); (2) análise de fotografias aéreas $1 / 25.000$ a preto/branco; (3) análise de MDT baseados em bases de dados topográficos 1/25.000 em suporte digital; (4) confirmação por reconhecimento de terreno. 
As evidências geomorfológicas do controlo local da drenagem pela tectónica resultaram da interpretação de vales assimétricos, padrões de drenagem, escarpas de falha, lineamentos tectóni$\cos$, vales controlados por fraturas e do desnivelamento vertical da superfície culminante do enchimento e de terraços.

\subsection{Litostratigrafia e sedimentologia}

O trabalho de campo compreendeu o levantamento de colunas estratigráficas nos principais afloramentos e caracterização sedimentológica dos depósitos sedimentares de modo a se obterem dados sobre as fácies deposicionais, incluindo a estrutura sedimentar, cor e textura do sedimento, o tamanho máximo (MPS) e a litologia dos clastos, o conteúdo fóssil, bem como a arquitetura deposicional.

\subsection{Datação absoluta}

\subsubsection{Datação por radiocarbono}

De amostras dos terraços do Baixo Tejo não existem publicadas idades de datação por radiocarbono, dada a escassez em materiais carbonáceos. Note-se que a curva de calibração mais precisa deste método só alcança $50 \mathrm{ka}$.

\subsubsection{Datação por Séries de Urânio}

$\mathrm{O}$ método por U-Th permite a datação de carbonatos, ossos e dentes fósseis, cuja idade esteja compreendida entre 10 e $350 \mathrm{ka}$. No caso dos ossos e dentes fósseis, o urânio só penetra neles depois da morte e enterramento dos animais e pode acontecer de várias formas (precoce ou progressiva), o que representa uma limitação na confiabilidade do método. O modelo de incorporação precoce dá uma idade mínima à amostra.

\subsubsection{Datação por luminescência}

A datação por luminescência é usada para determinar o tempo decorrido desde que: um sedimento foi pela última vez exposto à luz; ocorreu o último aquecimento de cerâmicas ou clastos (e.g. em fogueiras). Quando grãos minerais estão enterrados, eles recebem radiação ionizante proveniente de elementos radioactivos (e.g. Th, U e ${ }^{40} \mathrm{~K}$ ) existentes nos sedimentos próximos e também da radiação cósmica, a qual, tem alguma penetração em profundidade. A interacção das radiações ionizantes naturais com a matéria cristalina gera carga eléctricas que ficam retidas em armadilhas no edifício cristalino de minerais (e.g. quartzo, feldspato) e constituem a paleodose. Assim, é crucial que antes do enterramento de um material, ele tenha descarregado a energia latente anterior, processo designado por branqueamento (bleaching). $\mathrm{O}$ branqueamento permite que $\mathrm{o}$ "relógio" da contagem do tempo seja colocado a zero, pelo que, em caso contrário, a idade da amostra ficará sobrestimada. Em laboratório, na estimação da paleodose os grãos minerais habitualmente usados como dosímetros são o quartzo (Qz) e o feldspato potássico (Fk). Num equipamento leitor de luminescência, a estimulação pela luz ou calor permite obter a dose equivalente (De), expressa em Gray (Gy), pretendendo esta representar a paleodose. Assim, na datação por luminescência, a idade de uma amostra obtém-se dividindo a dose equivalente pela taxa de radiação ambiental (Dr, expressa em Gy/ka). As metodologias habitualmente usadas na datação por luminescência são sucintamente descritas em seguida.

Termoluminescência (TL; ThermoLuminescence), método baseado na emissão de luz induzida por aquecimento.

Luminescência Opticamente Estimulada (OSL; Optically Stimulated Luminescence), método baseado na emissão de luz induzida por estimulação de fotões. O método de rotina é por Qz-OSL, atualmente muito mais generalizado que o da datação por TL. Isto deve-se ao facto do sinal luminescente resultante da estimulação pela luz ser mais rapidamente e eficazmente "limpo" (branqueado) do que o sinal resultante da estimulação pela temperatura. Além disso, as frações medidas por TL são feitas em grãos muito finos (10-4 $\mu \mathrm{m})$, pelo que a sua composição plurimineral também não permite as necessárias correções às medições e também porque existem sedimentos desprovidos dessa fração de silte fino. A principal limitação do Qz-OSL está na saturação do sinal OSL, que geralmente ocorre a $\sim 200$ Gy. Assim, usando o protocolo SAR (WINTLE \& MURRAY 2006), a Qz-OSL permite datar sedimentos até cerca de 50 ka caso a taxa de radiação ambiental seja inferior a ca. $4 \mathrm{~Gy} / \mathrm{ka}$. Conclui-se que as datações Qz-OSL, apesar de precisas, são praticamente inviáveis para datar os terraços do rio Tejo, cujos sedimentos possuem altas doses de radiação ambiental (geralmente 3 a 7 Gy/ka; MARTINS \& CUNHA 2006a,b). Muito interessante é a recente possibilidade de se datarem superfícies de rocha (e.g. SOHBATI et al. 2012).

Luminescência estimulada em infra-vermelho (IRSL; Infra Red Stimulated Luminescence), método que usa o feldspato-k (Fk) como dosímetro. Quando a datação por Qz-OSL só fornece idade mínima (sinal saturado) este método é uma alternativa viável pois a saturação do sinal geralmente só ocorre aos $\sim 1000$ Gy. Contudo, as idades obtidas por IRSL precisam de ser corrigidas relativamente à perda de energia (anomalous fading) que ocorre nos grãos de Fk ao longo do tempo (WINTLE 1973) e mudanças de sensibilidade nos defeitos do cristal (WALLINGA 2002); estes dois fenómenos são ainda mal compreendidos e as correções são problemáticas. Infelizmente, na maior parte dos casos, os métodos de correção de fading não são adequados e geram subestimação nas idades obtidas (CUNHA 2010).

O protocolo pIRIR 290 usa o Fk como dosíme- 
tro e uma alta temperatura na estimulação pósIRIR (THOMSEN et al. 2008; BUYLAERT et al. 2009). Este método constitui a melhor alternativa atual para a datação de amostras que possuem o sinal Qz-OSL em saturação; tem fading irrelevante e pode fornecer resultados precisos até ca. $600 \mathrm{ka}$ (BUYLAERT et al. 2012).

\subsubsection{Datação por ressonância paramagnética electrónica}

A datação por ressonância paramagnética electrónica (Electron spin resonance - ESR) permite uma quantificação da concentração de radicais livres estáveis presentes numa amostra criados pela radiação ambiental, determinando-se a dose acumulada (De). Conhecendo-se a taxa de dose ambiental (Dr) no ponto de amostragem é possível obter-se a idade da amostra. Este método é não destrutivo, aplica-se a amostras de ossos, carbonatos, silicatos e a outros materiais isolantes elétricos (LAURENT et al. 1998; JOANNES-BOYAU 2014). Atendendo às habituais taxas de dose ambiental, este método permite obter datações precisas de depósitos sedimentares do Tejo com idades entre cerca de 300 ka e $8 \mathrm{Ma}$.

\subsubsection{Datação por nuclídeos cosmogénicos}

A datação por nuclídeos cosmogénicos (CRN; usando os isótopos ${ }^{10} \mathrm{Be}$ e ${ }^{26} \mathrm{Al}$ ) permite datar depósitos siliciclásticos com idades entre cerca de $400 \mathrm{ka}$ a $5 \mathrm{Ma}$ (e.g. YUAN et al. 2011. Este método é aplicável à datação dos terraços mais antigos do Baixo Tejo (T3, T2 e T1), bem como aos depósitos da unidade sedimentar culminante (SLD13).

\section{CARACTERIZAÇÃo DAS ESCADARIAS DE TERRAÇO}

\subsection{Troços do rio Tejo em Portugal}

No troço I, desenvolvido sobre o substrato sedimentar cenozoico e a montante do compartimento soerguido da falha do Ponsul - Arneiro, os seis níveis de terraço estão bem desenvolvidos no interior da depressão de Ródão. Neste troço há evidências de deslocamentos verticais e basculamentos afetando a unidade sedimentar culminante e os terraços, associados a vários sistemas de falhas (CUNHA et al. 2000a,b, 2005, 2008a; CARVALHO et al. 2006).

O troço II está escavado nas rochas metamórficas associadas ao compartimento soerguido delimitado pela falha do Ponsul - Arneiro e pela zona de falha do Gavião-Ortiga. Neste troço, o vale do Tejo praticamente não apresenta terraços sedimentares e apenas um terraço rochoso baixo (T6).

No troço III, como resultado do processo de epigenia, o rio Tejo apresenta um traçado transversal em relação às estruturas tectónicas do substrato, tendo escavado um vale estreito nas rochas duras do soco e desenvolvido um vale mais largo nas rochas brandas do Cenozoico, neste caso apresentando extensos terraços (Figs. 7e 8; Martins et al. 2009b). Neste troço a escadaria de terraços só está completa nas depressões tectónicas de Alvega, Rossio, Tramagal e Tancos com enchimento cenozoico e situadas a montante de compartimentos do soco cortados em estreito vale pelo Tejo.

No troço IV os terraços apresentam maior desenvolvimento, tanto no sentido transversal como no sentido longitudinal (Figs. 7 e 8). Aqui, o vale do Tejo encontra-se controlado por um sistema de falhas NNE-SSW (zona de falha do Vale

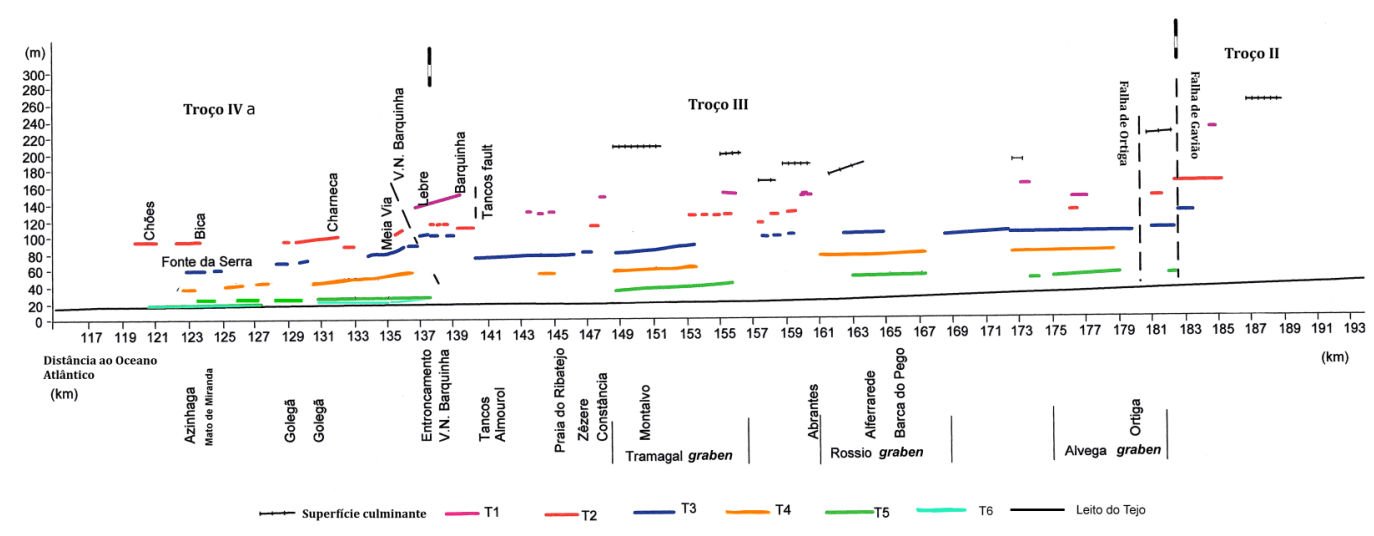

Fig. 7. Perfil longitudinal do rio Tejo, junto à margem direita, abrangendo o troço III e parte dos troços adjacentes. Representa-se o leito atual, bem como a superfície dos terraços (T1 a T6) e da unidade sedimentar culminante (CSS). Em abcissas indica-se a distância à foz, no Oceano Atlântico. Observa-se que a unidade sedimentar culminante e os terraços mais antigos estão localmente basculados e desnivelados, nomeadamente pelas falhas do Gavião, Ortiga e de Vila Nova da Barquinha (modificado de MARTINs et al. 2009b).

Fig. 7. Longitudinal profile of the Lower Tagus River and west side terraces, including reach III and the transition to the adjacent reaches. The distance upstream from the Atlantic shoreline is indicated (horizontal scale). The vertical displacement of the terraces induced by the Gavião and Ortiga faults and the terrace convergence downstream of the Vila Nova da Barquinha fault can be seen (modified from MARTINS et al. 2009b). 


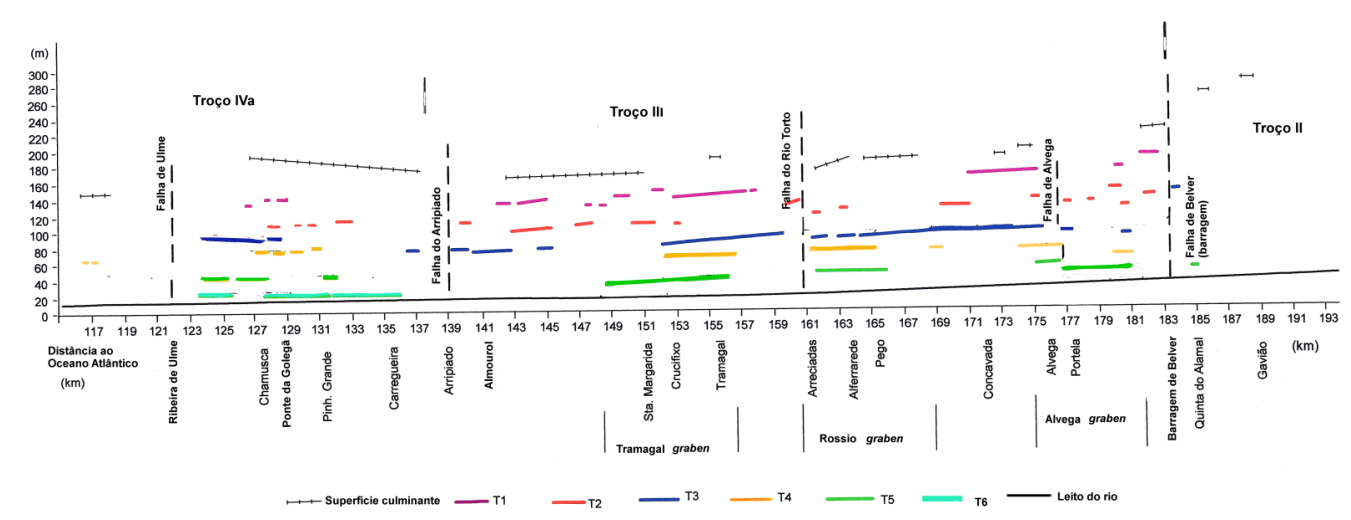

Fig. 8. Perfil longitudinal do rio Tejo, junto à margem esquerda, abrangendo o troço III e parte dos troços adjacentes. Representa-se o leito atual, bem como a superfície dos terraços (T1 a T6) e da unidade sedimentar culminante. Observa-se que a unidade sedimentar culminante e os terraços estão localmente basculados e desnivelados por várias falhas (modificado de MARTINS et al. 2009b).

Fig. 8. Longitudinal profile of the Tagus River and east side terraces, including reach III and the transition to adjacent reaches. The vertical displacement and tilting of the culminant unit and old terraces can be seen (modified from MARTINS et al. 2009b).

Inferior do Tejo) cuja presença foi assumida desde o início do séc. 20 (Bensaúde 1910; também existem falhas WNW-ESE. Na parte montante deste troço (designado por IVa), do Arripiado à Chamusca, os terraços apresentam menor largura, menor espessura e maior altitude do lado oriental do vale do que no lado ocidental. O desenvolvimento assimétrico dos terraços sugere que neste troço o Tejo está instalado num vale em ângulo de falha, com maior soerguimento relativo do compartimento oriental. Esta interpretação é confirmada através da análise geométrica dos terraços datados (MARTINS et al. 2008a,b,c, 2009a,b).

$\mathrm{O}$ troço $\mathrm{V}$ constitui o sector com menor soerguimento na bacia. Tal traduz-se por uma menor elevação da unidade sedimentar culminante e da escadaria de terraços, bem como por os terraços inferiores se encontrarem geralmente enterrados pelas aluviões holocénicas.

\subsection{Geomorfologia e estratigrafia}

A unidade culminante do enchimento sedimentar é a unidade alostratigráfica SLD13, correspondente aos depósitos do rio Tejo anteriores ao encaixe da rede hidrográfica (CUNHA 1992a, 1996). O seu registo sedimentar compreende a Formação de Falagueira, definida na Beira Baixa (e.g. Carvalho \& Daveau 1971; Cunha 1996) e os seus equivalentes laterais: Conglomerados de Serra de Almeirim/Arenitos de Ulme, no Ribatejo (BARBOSA 1995; BARBOSA \& ReIS 1996); Conglomerado de Belverde/Areias de Santa Marta/Areias de Coina, na Península de Setúbal (AzEvedo 1982). Esta unidade tem sido considerada com idade do Zancliano terminal ao Gelasiano (3,6 a 1,8 Ma; CUNHA et al. 1993, 2012). É interpretada como registando a captura de uma bacia previamente endorreica (Bacia Cenozoica de Madrid), pela rede fluvial Atlântica da Bacia Cenozoica do
Baixo Tejo (Fig. 9) (CunHA 1992a, 2008; CunHA et al. 1993, 2005; PÉreZ-GonZÁlez 1994; PEREIRA et al. 2015).

Tem uma espessura variando de $10 \mathrm{~m}$ (troço I) a $300 \mathrm{~m}$ (troço V). Consiste em cascalheiras arenosas e areias amareladas, com intercalações

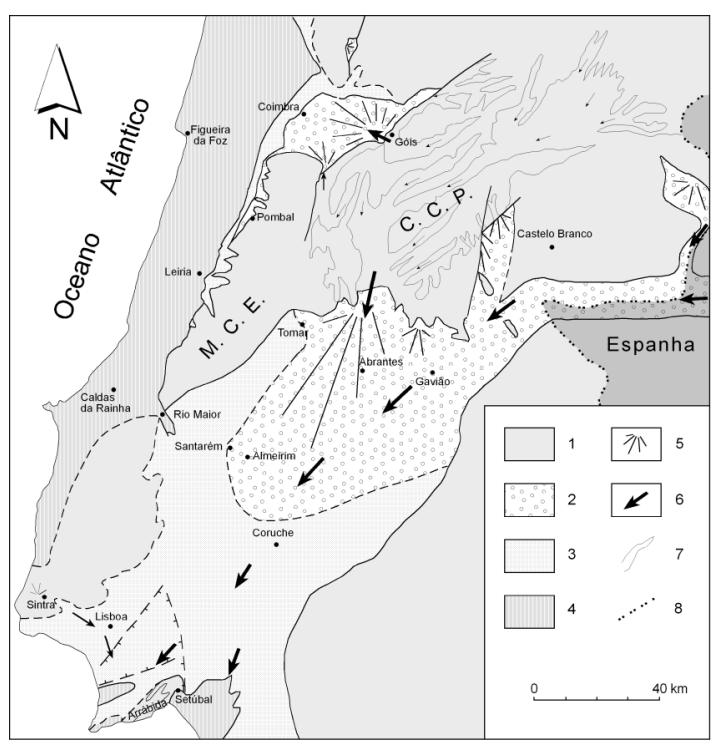

Fig. 9. Reconstituição paleogeográfica de Portugal central, na situação de máxima inundação marinha na transição Zancliano a Placenciano (modificado de Cunha \& Martins 2004). Legenda: 1 - área sem sedimentação; 2 - conglomerados aluviais; 3 - arenitos aluviais; 4 - sedimentos marinhos e de transição; 5 - leque aluvial; 6 - principal eixo de drenagem fluvial; 7 - vale; 8 - fronteira espanhola; M. C. E. - Maciço Calcário Estremenho; C. C. P. - Cordilheira Central Portuguesa.

Fig. 9. Paleogeographic reconstruction of central Portugal for the latest Zanclean to earliest Piacenzian (modified from Cunha \& Martins 2004). Legend: 1 - no sedimentation area; 2 - alluvial gravels; 3 - alluvial sands; 4 - coastal marine and transitional deposits; 5 - alluvial fan; 6 - main drainage axis; 7 - valley; 8 Spanish border; M. C. E. - Estremenho Limestone Massif; C. C. P. - Portuguese Central Cordillera. 
lutíticas cinzentas, cujos clastos são de quartzito $(80 \%)$ e quartzo leitoso. A CSS é a superfície de agradação a topo da unidade alostratigráfica SLD13 e a sua elevação (a.r.b.) decresce genericamente para jusante: no troço I, +160 a $262 \mathrm{~m}$; nos troços III a IV,+142 a $210 \mathrm{~m}$; no troço $\mathrm{V},+67 \mathrm{~m}$ (na Atalaia, a este de Montijo) a +65 a $80 \mathrm{~m}$ nas imediações da Lagoa da Albufeira (Península de Setúbal), mas elevando-se para a Serra da Arrábida (140200m).

Durante a etapa de progressivo encaixe da rede hidrográfica, o rio Tejo e os seus tributários desenvolveram uma sequência de seis níveis de terraço, muitas vezes associados lateralmente a coluviões, e o enchimento da planície aluvial (Fig. 10 e Quadro 1).

O terraço $\mathrm{T} 1$, aos +76 a $180 \mathrm{~m}$ (a.r.b.), tem uma espessura que varia de $13 \mathrm{~m}$ (troço I) a $>5 \mathrm{~m}$ (troço IVa). É constituído por cascalheiras de blocos com matriz arenosa, de cor vermelha, apresentando textura de suporte clástico e clastos de quartzito $(90-76 \%)$ e quartzo leitoso. Evidencia um solo vermelho enriquecido em argila.

$\mathrm{O}$ terraço T2 $(+57$ a $150 \mathrm{~m})$ tem uma espessura que varia de $4 \mathrm{~m}$ (troço I) a $7 \mathrm{~m}$ (troço IV). É constituído por cascalheiras de blocos com matriz arenosa, de cor castanho-vermelhada, com textura de suporte clástico e clastos de quartzito (80-69\%) e quartzo leitoso. Apresenta um solo avermelhado enriquecido em argila.

O terraço T3 (+36 a $113 \mathrm{~m})$ tem espessura de $4 \mathrm{~m}$ (troço I) a $10 \mathrm{~m}$ (troço IV). É constituído por cascalheiras de blocos com matriz arenosa, apresentando lentículas de areias muito grosseiras, de cor castanho-vermelhada; a textura é de suporte clástico e tem clastos de quartzito (78-44\%) e quartzo leitoso. Apresenta um solo avermelhado enriquecido em argila.

O terraço T4 $(+26$ a $55 \mathrm{~m})$ tem espessura de 1 -2 m (troço I) a 23-30 m (troço IV); é constituído por cascalheiras de blocos e matriz arenosa, de cor castanho-vermelhada, com textura de suporte clástico e clastos de quartzito (75-68\%) e quartzo leitoso. No troço IV este terraço apresenta uma espessa unidade superior constituída por areias alternantes com siltes argilosos (verdes a cinzentos); nestes últimos foram identificados rizomas de Nymphea e folhas de Salix e (ZBYSZEWSKI 1946), bem como um conteúdo polínico de Ericacea e Pinus (Montenegro DE ANDRAde 1944). Possui um solo avermelhado enriquecido em argila. As asso-

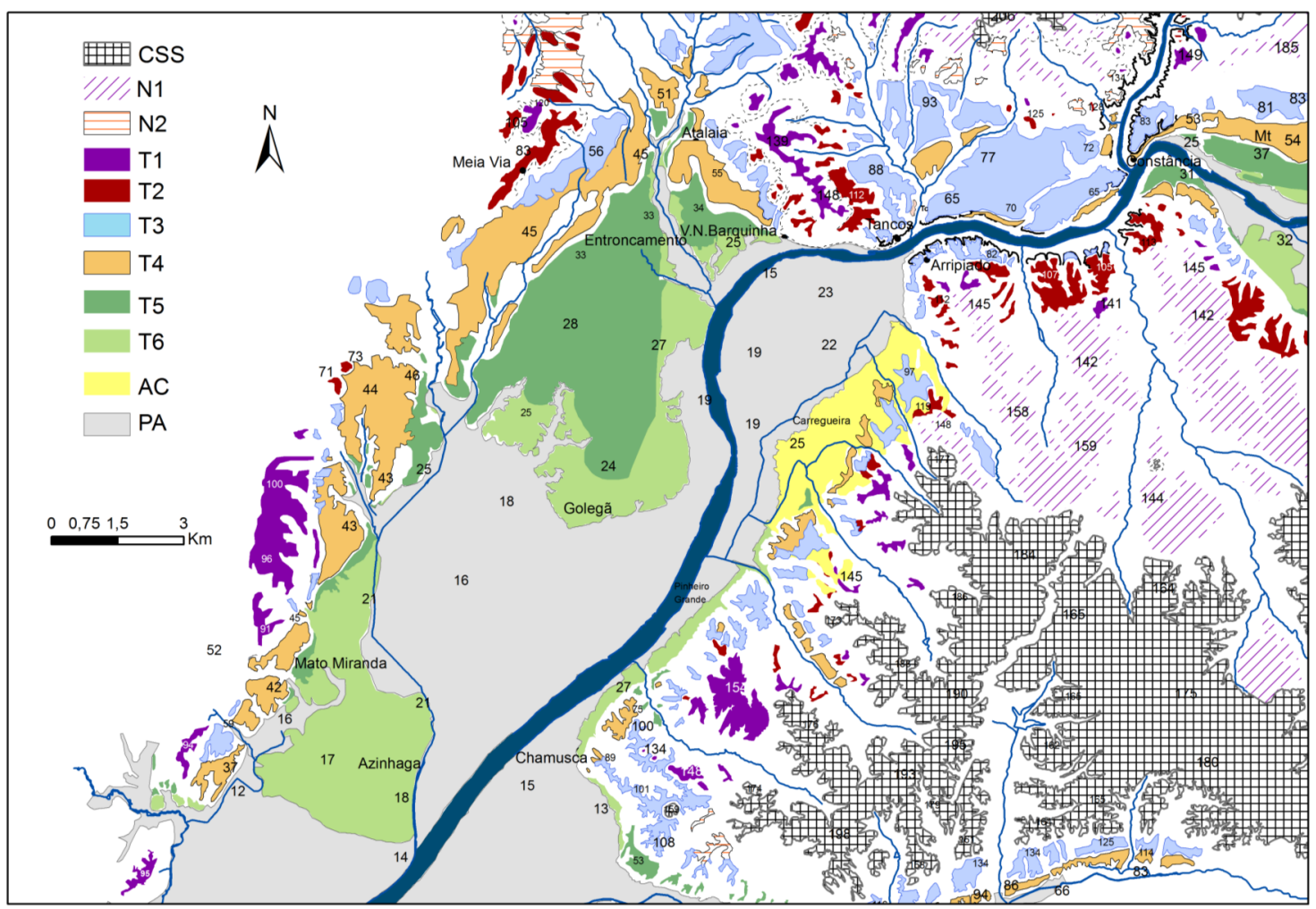

Fig. 10. Mapa geomorfológico do troço III (parte) e do troço IVa do Baixo Tejo. A assimetria no desenvolvimento espacial e vertical dos terraços resulta de atividade tectónica. CSS - superfície culminante da bacia cenozoica; N1 - superfície erosiva correlativa do terraço T1; N2 - superfície erosiva correlativa do terraço T2; T1 a T6 - terraços fluviais; AC - Areias da Carregueira (areias eólicas); PA - Planície aluvial.

Fig. 10. Geomorphological map of the Tagus River reach III (downstream part) and of the reach IV (SW-NE). The asymmetric spatial development of the terraces is related with active tectonics. CSS - culminant surface of the Cenozoic basin; N1 - erosion surface that links with the T1 terrace; N2 - erosion surface that links with the T2 terrace; T1 to T6 - terraces; AC - Carregueira Formation (aeolian sands); $\mathrm{PA}$ - alluvial plain. 
Quadro 1. Síntese dos principais atributos geológicos, geomorfológicos e arqueológicos da unidade sedimentar culminante e das sequências de terraço dos troços I a IVa do sector português do vale do Tejo (Ródão à Chamusca) e de alguns afluentes, com indicação da elevação (a.r.b.) e da idade.

Table 1. Summary of key geological, geomorphological and archaeological attributes for the culminant sedimentary unit and terrace sequences represented at the reaches I to IVa of the Lower Tejo River (Ródão to Chamusca) and some tributaries, with indication of the probable age and elevation a.r.b. $(\mathrm{m})$ of each surface.

\begin{tabular}{|c|c|c|c|c|}
\hline $\begin{array}{c}\text { Vila Velha de Ródão } \\
\text { - Feia/Remédios } \\
\text { Troço Ia } \\
\text { Cunha et al. (2008) }\end{array}$ & $\begin{array}{c}\text { Arneiro } \\
\text { - Vilas Ruivas } \\
\text { Troço Ib } \\
\text { Cunha et al. }(2012)\end{array}$ & $\begin{array}{l}\text { Gavião - Chamusca } \\
\text { Troços III e Iva } \\
\text { Martins et al. (2009) } \\
\text { Rosina et al. (2014) }\end{array}$ & $\begin{array}{c}\text { Vila Nova da } \\
\text { Barquinha, rios } \\
\text { Bezelga/Nabão e troço } \\
\text { IVa } \\
\text { Martins et al. }(2010 \mathrm{~b}) \\
\text { Rosina et al. }(2014)\end{array}$ & $\begin{array}{c}\text { Síntese das } \\
\text { indústrias líticas } \\
\text { nos } \\
\text { troços I a IV }\end{array}$ \\
\hline $\begin{array}{l}\text { Form. Falagueira (P) } \\
\text { 3,6 a 1,8? Ma } \\
\text { (Placenc.-Gelasiano) } \\
\quad+160 \text { a } 262 \mathrm{~m}\end{array}$ & $\begin{array}{l}\text { Form. Falagueira }(\mathrm{P}) \\
3,6 \text { a } 1,8 ? \text { Ma } \\
\text { (Placenc.-Gelasiano) } \\
+220 \mathrm{~m} ?\end{array}$ & $\begin{array}{c}\text { Form. Almeirim e Form. } \\
\text { Ulme (P) } \\
3,6 \text { a } 1,8 ? \mathrm{Ma} \\
+142 \text { a } 210 \mathrm{~m}\end{array}$ & $\begin{array}{c}\text { Form. Almeirim (P) } \\
\text { 3,6 a 1,8? Ma } \\
\text { (Placenc.-Gelasiano) } \\
+162 \mathrm{~m}\end{array}$ & Não encontradas \\
\hline $\begin{array}{c}\text { Terraço de Monte do Pinhal } \\
\text { (T1) } \\
\text { (Calabriano ?) } \\
+114 \text { a } 180 \mathrm{~m}\end{array}$ & $\begin{array}{l}\text { Leque aluvial e terraço } \\
\text { rochoso }(\mathrm{T} 1) \mathrm{em} \\
\text { quartzitos } \\
+153 \mathrm{~m}\end{array}$ & $\begin{array}{c}\text { Terraço T1 } \\
\text { 903 ka (ESR) } \\
\text { (Calabriano ?) } \\
+84 \text { a } 164 \mathrm{~m}\end{array}$ & $\begin{array}{c}\text { Terraço T1 } \\
\text { não datado } \\
\text { (Calabriano ?) } \\
+124 \mathrm{~m}\end{array}$ & Não encontradas \\
\hline $\begin{array}{c}\text { Terraço de Monte da Char- } \\
\text { neca (T2) } \\
\text { (Plistocénico Médio?) } \\
+87 \text { a } 150 \mathrm{~m} \\
\end{array}$ & $\begin{array}{c}\text { Terraço T2 } \\
\text { não datado } \\
\text { (Plistocénico Médio?) } \\
+108 \mathrm{~m} \\
\end{array}$ & $\begin{array}{c}\text { Terraço T2 } \\
\text { não datado } \\
\text { (Plistocénico Médio?) } \\
+57 \text { a } 112 \mathrm{~m} \\
\end{array}$ & $\begin{array}{c}\text { Terraço T2 } \\
\text { não datado } \\
\text { (Plistocénico Médio?) } \\
+92 \mathrm{~m} \\
\end{array}$ & Não encontradas \\
\hline $\begin{array}{c}\text { Terraço T3 } \\
\text { não datado } \\
\text { (Plistocénico Médio?) } \\
+67 \text { a } 113 \mathrm{~m}\end{array}$ & $\begin{array}{c}\text { Terraço T3 } \\
\text { não datado } \\
\text { (Plistocénico Médio?) } \\
+78 \mathrm{~m}\end{array}$ & $\begin{array}{c}\text { Terraço do Pego (T3) } \\
\sim 405 \text { e } 461 \text { ka (ESR) } \\
\text { (Plistocénico Médio) } \\
+43 \text { a } 73 \mathrm{~m}\end{array}$ & $\begin{array}{c}\text { Terraço T3 } \\
>310 \text { ka (IRSL) } \\
\text { (Plistocénico Médio) } \\
+57 \mathrm{~m}\end{array}$ & Não encontradas \\
\hline $\begin{array}{l}\text { Terraço de Monte do Fama- } \\
\text { co (T4) } \\
>280 \mathrm{ka} \text { (prov. } 340 \mathrm{ka}) \\
\text { a } \\
>135 \mathrm{ka} \text { (prov. } 154 \mathrm{ka}) \\
\text { (Plist. Médio- Sup.) } \\
+40 \text { a } 55 \mathrm{~m}\end{array}$ & $\begin{array}{c}\text { Terraço do Arneiro } \\
\text { (T4) } \\
>280 \mathrm{ka} \text { (prov. } 340 \mathrm{ka} \text { ) } \\
\text { a } \\
>\text { 135ka (prov. } 154 \mathrm{ka} \text { ) } \\
\text { (Plist. Médio-Sup.) } \\
+48 \mathrm{~m}\end{array}$ & $\begin{array}{l}\text { Terraço da Atalaia } \\
\text { (T4) } \\
\text { ca. } 340 \text { a } 154 \mathrm{ka} \\
\text { (Plist. Médio- Sup.) } \\
+26 \text { a } 50 \mathrm{~m}\end{array}$ & $\begin{array}{l}\text { Terraço da Atalaia (T4) } \\
\qquad 190 \text { a } 154 \mathrm{ka} \\
\text { (Plist. Médio- Sup.) } \\
+37 \mathrm{~m}\end{array}$ & $\begin{array}{c}\text { Paleolítico Inferior } \\
\text { (Acheulense) na base e } \\
\text { níveis intermédios; } \\
\text { Monte do Famaco, } \\
\text { Vale do Forno-Atela, } \\
\text { Fonte da Moita, } \\
\text { Rib. Ponte da Pedra; } \\
\text {--'----' } \\
\text { Paleolítico Médio inicial no } \\
\text { topo; Pegos do Tejo, } \\
\text { Vale do Forno 8 }\end{array}$ \\
\hline $\begin{array}{c}\text { Terraço da Sra. da Alagada } \\
\text { (T5) } \\
135 \text { a } 73 \mathrm{ka} \\
\text { (Plistocénico Superior) } \\
+22 \text { a } 34 \mathrm{~m} \\
\end{array}$ & $\begin{array}{c}\text { Terraço T5 } \\
113 \text { a } 78 \mathrm{ka}) \\
\text { (Plistocénico Superior) } \\
\text { +18 m; }\end{array}$ & $\begin{array}{c}\text { Terraço do Entroncamen- } \\
\text { to (T5) } \\
\sim 125 \text { a } 76 \mathrm{ka} \\
\text { (Plistocénico Superior) } \\
+5 \text { a } 28 \mathrm{~m}\end{array}$ & $\begin{array}{c}\text { Terraço do Entroncamen- } \\
\text { to (T5) } \\
\sim 125 \text { a } 90 \mathrm{ka} \\
\text { (Plistocénico Superior) } \\
+16 \mathrm{~m}\end{array}$ & $\begin{array}{c}\text { Paleolítico Médio } \\
\text { (Mustierense, Levallois); } \\
\text { Sra. Alagada, Vilas Ruivas, } \\
\text { Rib. Ponte da Pedra, Sto. } \\
\text { Antão do Tojal, Conceição }\end{array}$ \\
\hline $\begin{array}{c}\text { Terraço da Foz do Enxarri- } \\
\text { que (T6) } \\
39 \text { a } 32 \mathrm{ka} \\
\text { (Plistoc. Superior) } \\
+14 \mathrm{~m}\end{array}$ & $\begin{array}{c}\text { Depósitos aluviais e } \\
\text { Terraço T6 } \\
62 \text { a } 32 \mathrm{ka} \\
\text { (Plistoc. Superior) } \\
+10 \mathrm{~m}\end{array}$ & $\begin{array}{c}\text { Terraço da Azinhaga } \\
\text { (T6) } \\
51 \text { a } 39 \mathrm{ka} \\
\text { (Plistoc. Superior) } \\
+3 \mathrm{~m} \text { a } 10 \mathrm{~m}\end{array}$ & $\begin{array}{c}\text { Terraço da Azinhaga } \\
\text { (T6) } \\
62 \text { a } 30 \mathrm{ka} \\
\text { (Plistoc. Superior) } \\
+10 \mathrm{~m}\end{array}$ & $\begin{array}{l}\text { Paleolítico Médio final } \\
\text { (Mustierense final) } \\
\text { Foz do Enxarique, } \\
\text { Tapada do Montinho, } \\
\text { Santa Cita }\end{array}$ \\
\hline (Plistoc. Superior) & $\begin{array}{c}\text { Coluviões e areias } \\
\text { eólicas } \\
32 \text { a } 12 \mathrm{ka} \text {; } \\
\text { (Plistoc. Superior) }\end{array}$ & $\begin{array}{l}\text { Coluviões e areias eóli- } \\
\text { cas } \\
32 \text { a } 12 \mathrm{ka} \\
\text { (Plistoc. Superior) }\end{array}$ & $\begin{array}{l}\text { Coluviões e areias eóli- } \\
\text { cas } \\
30 \text { a } 12 \mathrm{ka} \\
\text { (Plistoc. Superior) }\end{array}$ & $\begin{array}{c}\text { Paleolítico Superior } \\
\text { a Epipaleolítico } \\
\text { Tapada do Montinho } \\
\text { Rib. Ponte da Pedra, Santa } \\
\text { Cita }\end{array}$ \\
\hline $\begin{array}{l}\text { Enchimento da planície } \\
\text { aluvial } \\
\text { (Plist. final - Holoc.) } \\
+8 \text { a } 0 \mathrm{~m}\end{array}$ & $\begin{array}{c}\text { Planície aluvial e } \\
\text { areias locais eólicas } \\
\text { (Plist. final - Holoc.) } \\
+7 \mathrm{~m}\end{array}$ & $\begin{array}{c}\text { Enchimento da planície } \\
\text { aluvial } \\
\text { (Plist. final - Holoc.) } \\
+2 \mathrm{~m}\end{array}$ & $\begin{array}{c}\text { Enchimento da planície } \\
\text { aluvial } \\
\text { (Plist. final - Holoc.) } \\
+2 \mathrm{~m}\end{array}$ & $\begin{array}{l}\text { Mesolítico e indústrias } \\
\text { mais recentes } \\
\text { (vários sítios) }\end{array}$ \\
\hline
\end{tabular}

ciações de minerais de argila podem estar dominadas pela ilite (Iks), vermiculite (Vki), caulinite (Kis) ou pela esmectite e caulinite (SKi). A goetite é responsável pela acentuada rubefação. Estas associações minerais sugerem clima temperado mediterrânico, com forte contraste estacional.

O terraço T5 $(+5$ a $34 \mathrm{~m})$ tem espessura de 8 m (troço I) a 9-10 m (troço IV); é constituído por uma unidade basal de cascalheira, sobreposta por uma areias grosseiras a finas e siltes argilosos com concreções carbonatadas pedogénicas, de cor esverdeada a cinzenta.

O terraço T6 (+3 a $14 \mathrm{~m})$ tem espessura de 6 $\mathrm{m}$ (troço I) a cerca de $18 \mathrm{~m}$ (troço IV); é constituí- do por areias grosseiras cascalhentas, sem matriz argilosa e com cor amarelada. Localmente pode ter uma base cascalhenta e um topo com intercalações de areias eólicas médias a finas e siltes. Os clastos são de quartzito e quartzo leitoso, com alguns de metagrauvaques. Não apresenta um perfil de alteração (solo). A fração argilosa é escassa e nela a ilite é o mineral de argila dominante.

Existe uma unidade de cobertura, constituída por areias eólicas grosseiras a finas, de cor esbranquiçada (Areias da Carregueira; MARTINS et al. 2010b; CunHA et al. 2012, 2015). Tem geralmente espessura inferior a $3 \mathrm{~m}$ mas localmente pode atinge $14 \mathrm{~m}$. Nos coluviões associados, a fração argilo- 
sa é escassa e nela a ilite é o mineral de argila dominante a exclusivo, refletindo condições climáticas frias e secas (Gomes et al. 2012).

A planície aluvial $(+2$ a $8 \mathrm{~m})$ culmina o enchimento do fundo do vale, com espessura $<4 \mathrm{~m}$ (troço I) a ca. $30 \mathrm{~m}$ (troço IVa) e geralmente compreende uma cascalheira basal, sobreposta por areias e intercalações de siltes argilosos (DAVEAU \& GONÇALVES 1985; VIS 2009).

\subsection{Datação absoluta}

A datação por $T h / U$ foi usada para datar: 3 dentes fósseis de um nível na base da unidade superior siltosa, sobreposto à unidade basal cascalhenta, do terraço T6 em Foz do Enxarrique (Vila Velha de Ródão; 32,9 $\pm 1,1 \mathrm{ka} ; 34,1 \pm 0,8 \mathrm{ka} ; 34,1$ $\pm 0,9 \mathrm{ka}$ ); uma tíbia de Elephas antiquus no T5 em Santo Antão do Tojal (a NE de Lisboa; 81,9 +4,0 3,8 ka) (RAPOSO 1995).

A datação por TL foi também usada para datar os depósitos dos terraços: Raposo (1995) publicou 2 idades do T5 de um afluente do Tejo, em Vilas Ruivas $(51+13-12 \mathrm{ka} ; 68+35-26 \mathrm{ka})$, bem como 4 idades mínimas do T4 em Vale do Forno $(127$ +infinito $-26 \mathrm{ka} ; 119$ +infinito $-32 \mathrm{ka}$; 117 +infinito $-26 \mathrm{ka}$; >124 ka); Raposo \& Cardoso (1998), do sítio da Conceição (Alcochete), apresentou datação do T5 $(74,5+11,6 /-10,4 \mathrm{ka})$ e da unidade eólica de cobertura $(27,2 \pm 2,5 \mathrm{ka})$; Cunha et al. (2008) apresentou idade de nível próximo do topo do T5, em V.V. Ródão ( 93 +20 -13 ka); A datação TL neste tipo de depósitos dificilmente fornece idades finitas $>90 \mathrm{ka}$ e é muito menos precisa do que a datação por OSL com protocolo SAR.

A primeira aplicação da datação por Qz-OSL com protocolo SAR foi em 8 amostras do terraço T4, tendo-se obtido idades mínimas de 148 a 191 ka (sinal Qz-OSL em saturação; Lab. S. Andrew, Escócia) (Martins 1999). Mais tarde, a estadia de seis meses de A.A. Martins no Nordic Laboratory for Luminescence Dating (NLL; Dinamarca) em 2005 visou a datação dos terraços inferiores do Baixo Tejo. Contudo, devido às elevadas doses de radiação apresentadas por este tipo de sedimentos fluviais, por Qz-OSL apenas se conseguiram algumas idades finitas do T6 e de areias eólicas das Arreias da Carregueira. Em 2006 foi P.P. Cunha que fez igual estadia no NLL recorrendo-se já à datação por IRSL (Fk) com correção do fading, obtendo-se, neste período e em anos seguintes, idades finitas do T6 (ca. 35 a 56 ka), T5 (ca. 99 a $136 \mathrm{ka})$ e T4 (ca. 136 a $277 \mathrm{ka}$ ), mas apenas idades mínimas do T3 $(>291 \mathrm{ka},>311 \mathrm{ka},>312 \mathrm{ka})$ (CUNHA et al. 2008, 2012; MARTINS et al. 2009b, 2010a, 2010b). Embora a idade obtida por IRSL para o T6 seja idêntica à finita de Qz-OSL numa mesma amostra, as idades IRSL determinadas para o T4 devem ser consideradas valores subestimados uma vez que foram obtidas usando o protocolo convencional IRSL a baixa temperatura $\left(50^{\circ} \mathrm{C}\right)$, para o qual o método usado na correção do fading (LAMOTHE et al. 2003) não é apropriado para amostras com sinal OSL próximo da saturação. Disso resulta uma significativa subestimação no cálculo das idades mais antigas. Devido à subestimação, Cunha et al. (2012) propôs que a fase de agradação do T4 deveria compreender o intervalo 160 a 340 ka.

Mais tarde, estas limitações na datação por luminescência de sedimentos mais antigos foram largamente ultrapassadas através do protocolo pIRIR 290 , que já foi usado na datação de terraços marinhos do Minho (CARVALHIDO et al. 2014), bem como de terraços fluviais dos rios Mondego (RAMOS et al. 2012) e Tejo (Alto Tejo - LóPEZRECIO et al. 2015; RoQUERO et al. 2015b; Baixo Tejo - CUNHA et al. in press).

A datação por ESR permitiu já obter idades do T4 topo $(299 \pm 14$ e $297 \pm 11 \mathrm{ka})$, do T4 base ( $260 \pm 35$ e $264 \pm 39 \mathrm{ka})$, do T3 topo $(405 \pm 76)$, do T3 base $(461 \pm 28 \mathrm{ka})$ e do T1 topo $(903 \pm 58 \mathrm{ka})$ (Rosina et al. 2014).

Estão em curso datações CRN na unidade culminante e nos terraços mais antigos, mas os resultados ainda não foram publicados.

Integrando todas as idades já obtidas pelos diversos métodos de datação absoluta é possível apresentar as idades dos intervalos de agradação dos terraços baixos e médios, nos troços I, III e IV: T6 - 32 ka a $62 \mathrm{ka} \mathrm{(30} \mathrm{ka);} \mathrm{T5} \mathrm{-} 73 \mathrm{ka} \mathrm{a} 135 \mathrm{ka}(62$ ka); T4 - $155 \mathrm{ka}$ a ca. $335 \mathrm{ka}$ (ca. $180 \mathrm{ka})$; T3 provavelmente ca. 360 ? a $460 \mathrm{ka}$ ) (ca 100? ka) (Fig. 11). Por diferença, também se pode estimar a duração das sucessivas fases de incisão fluvial: enchimento aluvial/T6 - $20 \mathrm{ka}$; T6/T5 - $11 \mathrm{ka}$; T5/ T4 - 20 ka; T4/T3 - ca. 25? ka. Assim, os dados indicam fases de escavamento e alargamento do vale relativamente curtas (ca. 11 a $25 \mathrm{ka}$ ), coincidindo com os períodos mais baixos do nível do mar (Fig. 11).

\subsection{Arqueologia}

Em algumas das unidades estratigráficas que resultaram da evolução do rio Tejo em Portugal foram identificadas indústrias líticas (Quadro 1; CUNHA et al. 2012): a unidade culminante do enchimento sedimentar - SLD13 (+142 a 262 m a.r.b.; com provável idade 3,6 a ca. 1,8 Ma), sem indústrias identificadas; T1 (+76 a $180 \mathrm{~m}$; ca. 1000 ? a $900 \mathrm{ka}$ ), sem indústrias; T2 (+57 a $150 \mathrm{~m}$; idade do topo estimada em ca. $600 \mathrm{ka})$, sem indústrias; T3 (+36 a $113 \mathrm{~m}$; ca. 460 a 360 ? ka), sem indústrias; T4 (+26 a 55 m; ca. 335 a 155 ka), Paleolítico Inferior (Acheulense) em níveis intermédios e da base do terraço mas Paleolítico Médio inicial em níveis do topo; T5 (+5 a 34 m; 135 a 73 ka), Paleolítico Médio (Mustierense, com fractura Levallois); T6 (+3 a $14 \mathrm{~m}$; 62 a $32 \mathrm{ka})$, Paleolítico Médio final 


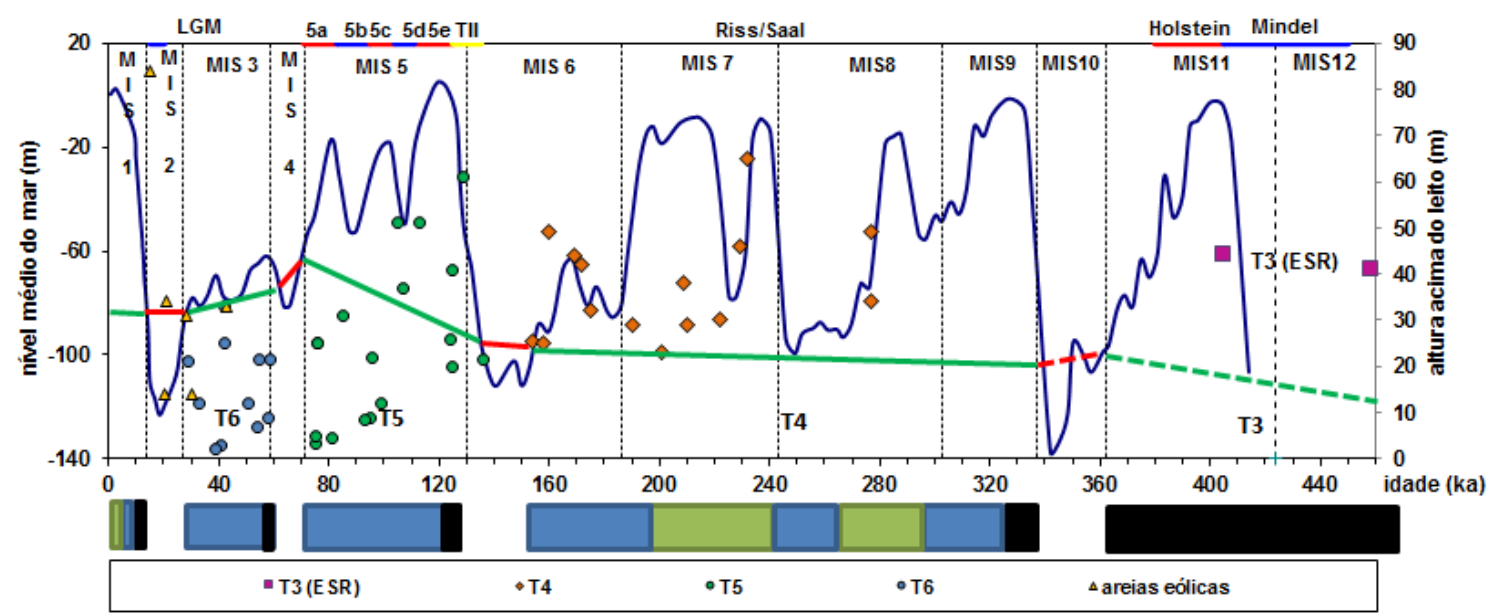

Fig. 11. Curva de variação eustática do nível médio do mar (isótopos da V19-30, segundo CUTLER et al. 2003) e projeção das idades (não mínimas) de OSL e ESR obtidas nos terraços T3 a T6 e areias eólicas. As barras horizontais representam as fácies de cada unidade sedimentar (preto - cascalheira; azul - areia; verde - argila siltosa) e o provável intervalo de idade da agradação de cada terraço. As areias eólicas pertencem às Areias da Carregueira. Para os troços estudados, os prováveis períodos com espaço de acomodação estão representados pelos segmentos verdes e os períodos de incisão e alargamento do vale estão representados por segmentos de cor vermelha. Os intervalos dos MIS estão de acordo com Lisiecki \& Raymo (2005).

Fig. 11. Eustatic mean sea level curve - scaled benthic isotopes from V19-30, after Cutler et al. (2003) and projection of the OSL and ESR ages (not minimum) obtained from samples collected from the T3 to T6 terraces and Carregueira Formation (aeolian sands). The lower horizontal bars illustrate the lithology (black - gravel; blue - sand; green - silty clay) and probable extent in age (aggradation interval) of each terrace. For the studied reaches, the probable intervals with significant accomodation space are represented by the green lines and the intervals with river downcutting and widening of the valley floor are represented by red lines. The boundaries of the Marine Isotope Stages are according to Lisiecki \& Raymo (2005).

(Mustierense final); Areias da Carregueira (areias eólicas) e coevos coluviões ( +3 a ca. $100 \mathrm{~m} ; 32$ a $12 \mathrm{ka}$ ), Paleolítico Superior a Epipaleolítico; e o enchimento da planície aluvial (+2 a $8 \mathrm{~m}$; ca. $12 \mathrm{ka}$ a actual), Mesolítico e indústrias mais recentes. Uma actualização sobre as indústrias paleolíticas associadas aos terraços da região foi feita, recentemente, por Oosterbeck et al. (2010), CunhaRibeiro (2011, 2013), Cura (2014) e Cunha et al. (2012, in press).

\subsection{Taxas de incisão fluvial}

A unidade sedimentar culminante (SLD13) e os níveis de terraço constituem referências geomórficas que registam a deformação associada com falhas ativas, que também se evidenciam nos relevos da Cordilheira Central Portuguesa (DAVEAU 1985). Permitem também calcular taxas de incisão, que podem ser usadas como proxy do soerguimento crustal, desde que tenha sido atingido um perfil longitudinal regularizado (e.g. MERRITTS et al. 1994; BURBANK et al.1996; MADDY 1997; BRIDGLAND 2000; MADDY et al. 2000; BURBANK \& ANDERSON 2001). Para se determinar uma taxa de incisão fluvial é necessário conhecer a idade da superfície de agradação final de um terraço e a diferença de elevação entre a superfície deste terraço e a do leito atual do respetivo curso de água. A superfície de um terraço representa o momento imediatamente anterior à fase de escavamento e formação de um novo patamar, embutido no anterior. Contudo, para se obter a taxa de incisão o melhor seria utilizar a idade do patamar (strath) subjacente aos depósitos de um terraço porque esta representa um perfil regularizado (situação de equilíbrio dinâmico, em que a taxa de incisão é aproximadamente igual à taxa de levantamento tectónico), enquanto a superfície do topo do enchimento sedimentar materializa a culminação de uma fase mais tardia de agradação sedimentar. Contudo, os materiais da base de um terraço são geralmente de mais difícil datação.

Para uma dada escadaria de terraços, a taxa de incisão obtêm-se através do declive da curva de regressão obtida projetando a idade da superfície dos diferentes terraços em função das respetivas alturas acima do leito atual. As maiores dificuldades na datação dos terraços surgem, nuns casos porque os terraços são demasiado antigos, estando fora do alcance das técnicas disponíveis, noutros porque as características dos seus sedimentos limitam consideravelmente as metodologias aplicáveis (e.g. taxa de radiação ambiental, no caso da datação por luminescência). Os terraços do rio Tejo, e muito provavelmente os da maioria dos rios portugueses, apresentam as dificuldades atrás referidas (MARTINS \& CUNHA 2006a,b).

Uma aceleração das taxas de incisão de longo -termo durante o Quaternário foi evidenciada em muitas sequências de terraços nos USA (e.g., HANCOCK et al. 1999; PATTON et al. 1991; REHEIS et al. 1991; REPKA et al. 1997) e na Europa (rios Thames, Rhine-Meuse, Loire-Allier, etc; e.g., BRIDGLAND 2000; LANCASTER 2005), podendo resultar da actuação de um ou mais dos controlos alocíclicos. Contudo, Mills (2000) propôs que essa 
aparente aceleração seria um artefacto resultante do cálculo da taxa de longo-termo se fazer com períodos mais curtos à medida que a idade da referência diminui. Os nossos dados permitem testar a validade desta hipótese para o Baixo Tejo. Assim, no Quadro 2 apresentam-se as taxas de incisão de longo-termo do rio Tejo obtidas para escadarias dos troço I, III e IVa, tendo-se usado a idade da superfície do enchimento sedimentar de cada referência, devido à dificuldade de datação da superfície da base dos depósitos. Por exemplo, para a escadaria da margem direita do Tejo em Rodão, verifica-se que a taxa de incisão de longo-termo aumenta para tempos mais recentes (de 0,09 a 0,44 $\mathrm{m} / \mathrm{ka}$ ) (Quadro 2; Fig. 12). A mesma aceleração também se verifica analisando as sucessivas taxas

Quadro 2. Taxas de incisão de longo-termo nos troços I a IV do rio Tejo português calculadas com base na idade da superfície de cada nível de terraço, em diferentes escadarias da área de estudo. Ver também a Fig. 13, para localização.

Table 2. Long-term incision rates for reaches I to IVa of the Portuguese Tagus River, determined by using the age of the surface of each terrace, in several terrace staircases of the study area. For location, see Fig. 13.

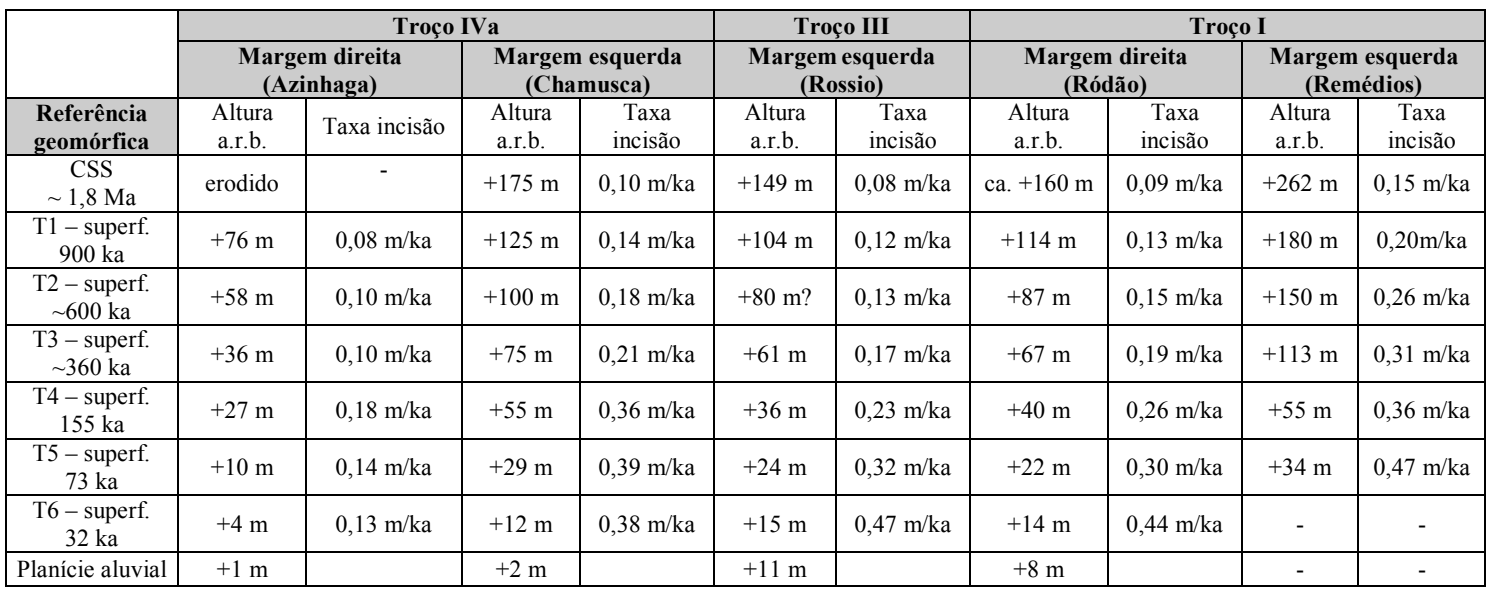

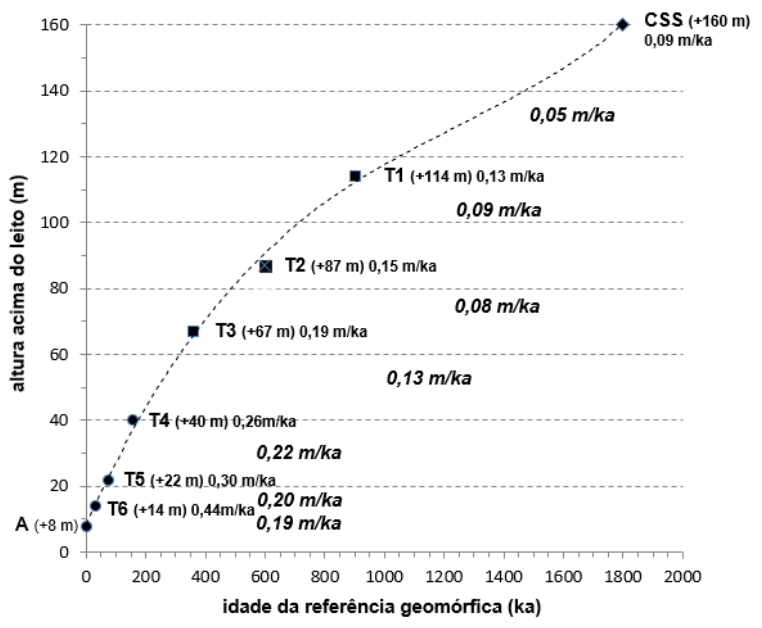

Fig. 12. Projeção da elevação (a.r.b) função da respetiva idade, das diversas referências geomórficas da escadaria na margem direita do rio Tejo, em Vila Velha de Ródão (troço Ia). Por interpolação estima-se uma idade de ca. 600 ka para a superfície do T2; por extrapolação, estima-se uma idade de ca. 1,8 Ma para a CSS. Note-se que a superfície deposicional dos leques aluviais finicenozoicos da Sierra Morena (Raña espanhola) foi datada em ca. 1,7 Ma (Escudero \& Olmo 1997), numa posição geomorfológica similar à da SLD13. Para cada referência apresenta-se a respetiva taxa de incisão de longo-termo; também se apresentam os valores de taxa de incisão de curto-termo calculados entre duas referências sucessivas (valores em itálico). Constata-se que nos últimos $155 \mathrm{ka}$ a taxa de incisão (terraço T4 à Planície aluvial: $32 \mathrm{~m} / 155 \mathrm{ka}=0,21 \mathrm{~m} / \mathrm{ka}$ ), apresenta um valor duplo da taxa que se determina para o intervalo $155 \mathrm{ka}$ a $900 \mathrm{ka}($ terraços T1 a T4: $74 \mathrm{~m} / 745 \mathrm{ka}=0,10 \mathrm{~m} / \mathrm{ka})$.

Fig. 12. For the Enxarrique - Monte do Pinhal terrace staircase (Ródão depression, reach Ia), the ages of the sedimentary top surface of the alluvial plain and T6, T5, T4 and T1 terraces are plotted against height above the Tagus river bed. The age of the T2 surface is obtained by interpolation, as $600 \mathrm{ka}$. By extrapolation, an age of ca. $1.8 \mathrm{Ma}$ is obtained for the CSS (black lozenge), considered the beginning of the incision stage of the Tagus River. Note that the depositional surface of the Sierra Morena central alluvial fans (Spanish raña; Madrid basin) was dated as ca. 1.7 Ma (Escudero \& Olmo 1997), in a similar geomorphologic position as the SLD13. Long-term incision rates and short-term incision rates are presented. For the last 155 ka (black circles) the average incision rate (T4 to alluvial plain: $32 \mathrm{~m} / 155 \mathrm{ka}=0.21 \mathrm{~m} / \mathrm{ka}$ ), is twice the value determined for the interval $155 \mathrm{ka}$ to $900 \mathrm{ka}$ (terraces T1 to T4: $74 \mathrm{~m} / 745 \mathrm{ka}=0.10 \mathrm{~m} / \mathrm{ka})$. 
de incisão de curto-termo (Quadro 3; Fig. 12): 0,05 $\mathrm{m} / \mathrm{ka}(160-114 \mathrm{~m}) /(1800-900 \mathrm{ka}) ; 0,09 \mathrm{~m} / \mathrm{ka}(114-$ $87 \mathrm{~m}) /(900-600 \mathrm{ka}) ; \quad 0,08 \mathrm{~m} / \mathrm{ka} \quad(87-67 \mathrm{~m}) /(600-$ $360 \mathrm{ka}) ; 0,13 \mathrm{~m} / \mathrm{ka}(67-40 \mathrm{~m}) /(360-155 \mathrm{ka}) ; 0,22 \mathrm{~m} / \mathrm{ka}$ $(40-22 \mathrm{~m}) /(155-73 \mathrm{ka}) ; \quad 0,20 \mathrm{~m} / \mathrm{ka} \quad(22-14 \mathrm{~m}) /(73-$ $32 \mathrm{ka}) ; \quad 0,19 \mathrm{~m} / \mathrm{ka} \quad(14-8 \mathrm{~m}) /(32-0 \mathrm{ka})$. Assim, os resultados evidenciam que, num mesmo compartimento tectónico, as taxas de incisão de curto-termo obtidas para os sucessivos níveis de terraço de uma mesma escadaria, são aproximadamente constantes nos últimos $155 \mathrm{ka}$ e apresentam valor duplo da taxa que se determina para o intervalo anterior (155 a ca. $900 \mathrm{ka})$.

Nas escadarias estudadas em pormenor, o compartimento com maior soerguimento diferencial (maior taxa de incisão) é o da margem esquerda do Tejo no troço I (Remédios) e o com menor soerguimento é o da margem direita do Tejo no troço IVa (Entroncamento-Azinhaga), este claramente desnivelado pela zona de falha do Vale Inferior do Tejo (NNE-SSW) relativamente à escadaria da margem esquerda (Arripiado-Chamusca) (Fig. 13).

Quadro 3. Taxas de incisão de curto-termo nos troços I a IV do rio Tejo português calculadas com base na diferença de elevação de duas sucessivas referências geomórficas dividida pela respectiva diferença de idades, em diferentes escadarias da área de estudo. Ver também o Quadro 2 e a Fig. 13.

Table 3. Short-term incision rates for reaches I to IVa of the Portuguese Tagus River, determined by using the difference in elevation and age of two successive geomorphic references, in several terrace staircases of the study area. Also see Table 2 and Fig. 13.

\begin{tabular}{|c|c|c|c|c|c|}
\hline \multirow{2}{*}{ Referências geomórficas } & \multicolumn{2}{|c|}{ Troço IVa } & Troço III & \multicolumn{2}{c|}{ Troço I } \\
\cline { 2 - 6 } & $\begin{array}{c}\text { Margem direita } \\
\text { (Azinhaga) }\end{array}$ & $\begin{array}{c}\text { Margem esquer- } \\
\text { da (Chamusca) }\end{array}$ & $\begin{array}{c}\text { Margem esquerda } \\
\text { (Rossio) }\end{array}$ & $\begin{array}{c}\text { Margem direita } \\
\text { (Ródão) }\end{array}$ & $\begin{array}{c}\text { Margem esquerda } \\
\text { (Remédios) }\end{array}$ \\
\hline CSS/T1 (900 ka) & - & $0,06 \mathrm{~m} / \mathrm{ka}$ & $0,05 \mathrm{~m} / \mathrm{ka}$ & $0,05 \mathrm{~m} / \mathrm{ka}$ & $0,09 \mathrm{~m} / \mathrm{ka}$ \\
\hline T1/T2 (300 ka) & $0,06 \mathrm{~m} / \mathrm{ka}$ & $0,08 \mathrm{~m} / \mathrm{ka}$ & $0,08 \mathrm{~m} / \mathrm{ka}$ & $0,09 \mathrm{~m} / \mathrm{ka}$ & $0,10 \mathrm{~m} / \mathrm{ka}$ \\
\hline T2/T3 (240 ka) & $0,09 \mathrm{~m} / \mathrm{ka}$ & $0,10 \mathrm{~m} / \mathrm{ka}$ & $0,08 \mathrm{~m} / \mathrm{ka}$ & $0,08 \mathrm{~m} / \mathrm{ka}$ & $0,15 \mathrm{~m} / \mathrm{ka}$ \\
\hline T3/T4 (205 ka) & $0,04 \mathrm{~m} / \mathrm{ka}$ & $0,10 \mathrm{~m} / \mathrm{ka}$ & $0,10 \mathrm{~m} / \mathrm{ka}$ & $0,13 \mathrm{~m} / \mathrm{ka}$ & $0,28 \mathrm{~m} / \mathrm{ka}$ \\
\hline T4/T5 (82 ka) & $0,21 \mathrm{~m} / \mathrm{ka}$ & $0,32 \mathrm{~m} / \mathrm{ka}$ & $0,15 \mathrm{~m} / \mathrm{ka}$ & $0,22 \mathrm{~m} / \mathrm{ka}$ & $0,26 \mathrm{~m} / \mathrm{ka}$ \\
\hline T5/T6 (41 ka) & $0,15 \mathrm{~m} / \mathrm{ka}$ & $0,41 \mathrm{~m} / \mathrm{ka}$ & $0,22 \mathrm{~m} / \mathrm{ka}$ & $0,20 \mathrm{~m} / \mathrm{ka}$ & - \\
\hline T6/P1.Al. (32ka) & $0,09 \mathrm{~m} / \mathrm{ka}$ & $0,31 \mathrm{~m} / \mathrm{ka}$ & $0,13 \mathrm{~m} / \mathrm{ka}$ & $0,19 \mathrm{~m} / \mathrm{ka}$ & - \\
\hline
\end{tabular}

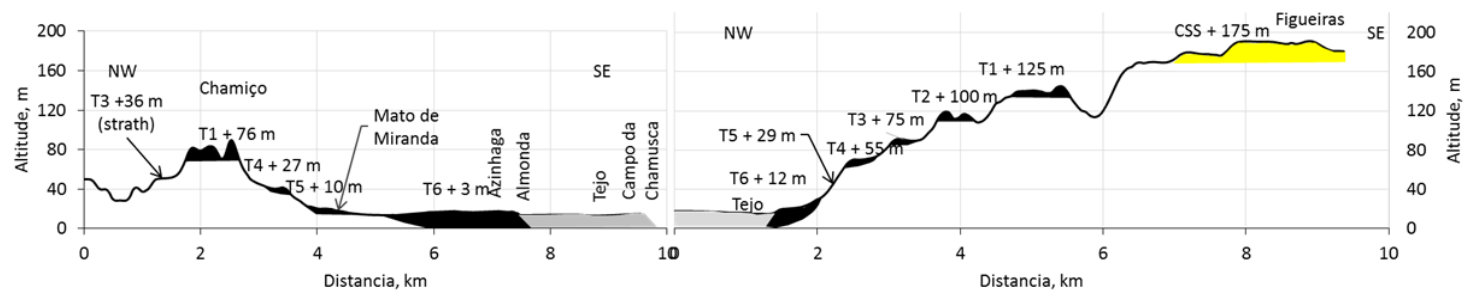

Fig. 13. Comparação da escadaria da margem direita com a da margem esquerda, no troço IVa (ver a Fig. 10, para localização do transepto). Evidencia-se um maior escalonamento dos terraços na margem esquerda, por desnivelamento vertical promovido pela zona de falha do Vale Inferior do Tejo.

Fig. 13. Comparison of the west side staircase with the east side staircase in reach IVa (for location see Fig. 10). The terrace levels at the east side staircase are at higher elevation than the ones presented by the west side staircase (vertical displacement by the Lower Tagus Valley fault zone).

\section{DISCUSSÃO}

O forte debate que ainda existe sobre o predomínio do controlo climático, eustático ou tectónico na génese de escadarias de terraços fluviais resulta em grande parte das limitações dos métodos de datação disponíveis e das coleções de idades (sua qualidade e quantidade) existentes para uma dada sequência de terraços. Tendo em conta as unidades sedimentares fluviais quaternárias datadas do rio Tejo na área de estudo (Fig. 11) - terraço T3 - ca. 460 a 360 ? ka (100? ka); T4 - ca. 335 a $155 \mathrm{ka}(180 \mathrm{ka}) ; \mathrm{T} 5$ - 135 a $73 \mathrm{ka}(62 \mathrm{ka}) ; \mathrm{T} 6$ - 62 a $32 \mathrm{ka} \mathrm{(30} \mathrm{ka);} \mathrm{enchimento} \mathrm{da} \mathrm{planície} \mathrm{aluvial} \mathrm{-}$ ca. $12 \mathrm{ka}$ a atual) — conclui-se que durante o Plistocénico médio e final, as fases de incisão e alargamento do vale foram curtas (ca. 11-25 ka) e ocorreram durante os períodos de nível do mar muito baixo, alternando com mais longas fases de inundação e agradação do vale durante níveis do mar mais altos. Este controlo por um nível de base glácio-eustático (pelo Oceano Atlântico) esteve sobreposto a um contexto de soerguimento refletido por taxas de incisão de longo-termo da ordem dos 0,15 aos $0,09 \mathrm{~m} / \mathrm{ka}$ nos últimos $1,8 \mathrm{Ma}$. As variações 
climáticas de mais curto período também controlaram o fornecimento sedimentar e o regime de caudais, como se reflete no intervalo de agradação e tipo de litologias de cada terraço (Fig. 11). Contudo, para se poder avaliar mais detalhadamente a variabilidade climática neste tipo de arquivos fluviais, a uma escala de $10^{3}$ anos ou com maior pormenor, é necessário ter um elevado número de idades (finitas e precisas) em sucessão estratigráfica.

Relativamente ao tipo de clima coevo da formação das unidades estudadas, a SLD13 depositou-se sob clima quente e húmido, com muito boa drenagem (CUNHA 2000). O solo de tipo argiloso e com rubefação típico dos terraços T1, T2, T3 e T4 permite supor clima temperado de tipo mediterrânico com forte contraste estacional. O terraço T5 não possui rubefação, podendo ser inferidas condições temperadas mais húmidas. $\mathrm{O}$ terraço $\mathrm{T} 6$ não exibe este tipo de paleo-alterações e os dados sedimentológicos indicam que se formou sob um clima frio e húmido tal como o caracterizado para este intervalo (62 a $32 \mathrm{ka}$ ) nesta região (e.g. Roucoux et al. 2005; SALGUEIRO et al. 2010). Enterrado sob o enchimento holocénico dos troços V e IV deverá existir ainda um terraço T7, correlativo de um clima frio e seco que na área de estudo gerou a unidade de cobertura formada por areias eólicas ( 32 a 12 ka) (e.g. RouCOUX et al. 2005, 2006; CunHA et al. 2012, 2015). O enchimento holocénico depositouse sob um clima temperado genericamente similar ao actual.

Na Bacia de Madrid (Alto e Médio Tejo), estão identificados, no vale do Tejo e nos vales dos seus tributários, um máximo de 16 níveis de terraço (não considerando os "terraços ranizos" localizados na cabeceira de leques aluviais), que foram datados pela combinação da datação absoluta com dados paleomagnéticos (e.g. SILVA et al. 2013b; ROQUERO et al. 2015a). Os mais antigos materiais Paleolíticos são ocorrências isoladas de grandes lascas de sílex, de aparente talhe de tipo Acheulense inicial, associadas com terraços aos +100 a 107 $\mathrm{m}$ a +80 a $85 \mathrm{~m}$ (provavelmente com idades entre ca. 1,4 e 1,2 Ma) (RUBIO-JARA et al. 2016). Indústrias Acheulenses foram encontradas em terraços aos +70 a $78 \mathrm{~m}$ (provavelmente ca. 1,1 a $1,0 \mathrm{Ma}$ ) a +18 a $22 \mathrm{~m}$ (ca. 135 a $74 \mathrm{ka}$ ); este último terraço tem níveis estratigráficos superiores contendo indústrias do Paleolítico Médio, com talhe Mustierense. Sítios Mustierenses foram também encontrados em terraços situados entre +15 a $13 \mathrm{~m} \mathrm{a}+8$ a $10 \mathrm{~m}$ (com idades de ca. 60 a $28 \mathrm{ka}$ ) (e.g. SANTONJA \& PÉREZ-GONZÁlez 2010; PÉREZ-GONZÁlEZ et al. 2013; PANERA et al. 2014; LÓPEZ-RECIO et al. 2015; ROQUERO et al. 2015a,b; RUBIO-JARA et al. 2016). No Alto-Médio Tejo e no Baixo Tejo, as indústrias do Paleolítico Superior são geralmente encontradas associadas com coluviões e areias eólicas (ca. 30 a 12 ka; e.g. MARTINS et al. 2010b; CUNHA et al. 2012; LÓPEZ-RECIO et al. 2015).

Merece ser referido que a coleção mais completa de artefactos associados a uma associação faunística "de clima quente" foi encontrada nos sítios Acheulenses de Pinedo e Cien Fanegas (vale do Alto Tejo, junto a Toledo) no terraço aos +25 a $30 \mathrm{~m}$, cujos depósitos do topo foram datados por AAR (Amino-Acid Racemization) de $226+37 \mathrm{ka}$ e nos depósitos da base foram obtidas idades de $>280$ ka e $292+17 \mathrm{ka}$ (pIR-IRSL) (LÓPEZ-RECIO et al. 2015). Pelo exposto se conclui que este terraço se correlaciona bem com o terraço T4 $(+26$ a $63 \mathrm{~m})$ do Baixo Tejo.

Contudo, não há ainda um número suficiente de idades que possam suportar uma correlação detalhada entre as escadarias do Alto-Médio Tejo (em Espanha, com 16 níveis de terraços fluviais) e as do Baixo Tejo (em Portugal, somente com 6 níveis de terraços). É necessário salientar que os controlos sedimentares da formação das escadarias do Baixo Tejo e do Alto-Médio Tejo são distintas, pois no perfil longitudinal do rio Tejo existe uma larga e permanente zona de quebra de pendor (knickzone do substrato Paleozóico) entre as duas bacias. No Baixo Tejo existiu sempre um controlo dominado pelo glácio-eustatismo, cuja influência não se repercute no Alto-Médio Tejo, demasiado afastado do nível de base Atlântico e separado do Baixo Tejo pela knickzone atrás referida. Além disso, no Baixo Tejo, entre os diversos troços em apreço, existiu soerguimento diferencial suficiente para explicar as diferentes alturas acima do leito de um mesmo nível de terraço.

No que respeita às taxas de levantamento tectónico regional, a área de estudo evidencia movimentos verticais durante o Pliocénico Superior e Quaternário com taxas de soerguimento de longo-termo semelhantes aos estimados para a faixa litoral $(0,1$ a $0,2 \mathrm{~m} / \mathrm{ka}$; CABRAL 1993, 1995, 2012). Assim, tendo como referência a superfície (CSS, com ca. 1,8 Ma) da unidade culminante plioplistocénica (SLD13), nos diversos compartimentos tectónicos da área de estudo obtiveram-se taxas de incisão de longo-termo variando de 0,09 a 0,15 $\mathrm{m} / \mathrm{ka}$. Entendemos que as diferenças na taxa de incisão nos vários compartimentos estudados (troços I a IVa) se devem a soerguimento diferencial gerado por vários sistemas de falhas ativas. A duplicação do valor da taxa de incisão fluvial nos últimos ca. $155 \mathrm{ka}$ deverá resultar do aumento da taxa de soerguimento litosférico regional que se vem evidenciando por intensificação do contexto de compressão horizontal resultante da convergência, segundo NW-SE e a $\sim 4 \mathrm{~mm} / \mathrm{a}$, entre as placas Euroasiática e Africana (DEMETS et al. 1994, 2010; RIBEIRO et al. 1996; MARTÍN-VELÁZQUEZ et al. 2016). 


\section{CONCLUSÕES}

Em todas as escadarias do Baixo Tejo confirma -se a existência de um número máximo de seis níveis de terraços fluviais (T1 a T6), escalonados abaixo da unidade culminante do enchimento sedimentar (SLD13) e acima da respetiva planície aluvial.

À superfície da unidade sedimentar culminante (CSS) e às de cada um dos níveis de terraço e da planície aluvial (A), nos troços I a IVa, pôde ser atribuído um intervalo de elevação acima do respectivo leito atual do Tejo (a.r.b.): CSS +142 a $262 \mathrm{~m}$; T1 +84 a $180 \mathrm{~m}$; T2 +57 a $150 \mathrm{~m}$; T3 +43 a $113 \mathrm{~m}$; T4 +26 a $55 \mathrm{~m}$; T5 +5 a $34 \mathrm{~m}$; T6 +3 a $14 \mathrm{~m}$; $\mathrm{A}+2$ a $8 \mathrm{~m}$. Salienta-se que, a jusante da Chamusca, o terraço mais baixo (T6) se encontra enterrado nas aluviões.

$\mathrm{O}$ intervalo de elevação a.r.b. dos vários níveis é pequeno a nível local mas muito amplo à escala do Baixo Tejo, devido a que o escalonamento dos seis terraços de cada escadaria varia localmente, quer ao longo do vale, quer entre as escadarias das margens opostas de um mesmo troço do rio Tejo.

$\mathrm{O}$ desigual desenvolvimento espacial e vertical das escadarias de terraço resulta de soerguimento diferencial, promovido pela movimentação em falhas transversais e longitudinais ao desenvolvimento do vale. Esta tectónica ativa evidencia-se por desnivelamentos e basculamentos dos níveis de terraço e da unidade culminante, com evidências maiores nos elementos geomórficos mais antigos. Os dados existentes ainda são insuficientes para uma adequada caracterização do risco sísmico e, portanto, o desenvolvimento deste tipo de estudos deve ser considerado prioritário.

A utilização de diversos métodos de datação absoluta permitiu obter a duração dos intervalos de agradação dos terraços baixos e médios, nos troços I, III e IVa: T6 - 32 a $62 \mathrm{ka}(30 \mathrm{ka}) ; \mathrm{T} 5-73$ a 135 ka (62 ka); T4 - 155 a ca. 335 ka (ca. $180 \mathrm{ka})$; T3 ca. 360 ? a $460 \mathrm{ka}(100$ ? ka). Para os terraços médios e baixos, bem como o enchimento da planície aluvial, todos precisamente datados, conclui-se que as fases de incisão seguidas de alargamento do vale são curtas (ca. 11 a $25 \mathrm{ka}$ ) e coincidiram com períodos de muito baixo nível do mar. Para se conhecer o intervalo de agradação dos terraços mais antigos (T2 e T1) e da unidade culminante do enchimento sedimentar (SLD13), será necessário datar por CRN e ESR.

As várias unidades estratigráficas que resultaram da evolução do rio Tejo em Portugal possuem distintas indústrias líticas: a SLD13 (com provável idade 3,6 a 1,8 Ma), sem artefactos identificados; T1 (ca. 1000? a $900 \mathrm{ka}$ ), sem artefactos identificados; T2 (idade do topo estimada em ca. $600 \mathrm{ka}$ ), sem artefactos identificados; T3 (ca. 460 a 360 ? ka), sem artefactos identificados; T4 (ca. 335 a $155 \mathrm{ka}$ ), Paleolítico Inferior (Acheulense) em níveis intermédios e da base do terraço mas Paleolítico Médio inicial em níveis do topo; T5 (135 a 73 ka), Paleolítico Médio (com talhe Mustierense, Levallois); T6
(+3 a $14 \mathrm{~m} ; 62$ a $32 \mathrm{ka}$ ), Paleolítico Médio final (Mustierense final); Areias da Carregueira (areias eólicas) e coluviões (32 a 12 ka), Paleolítico Superior a Epipaleolítico; e o enchimento da planície aluvial (12 ka a atual), Mesolítico e indústrias mais recentes. Tendo em conta que em Espanha, quer na Bacia do Alto Tejo, quer na bacia do Douro, os mais antigos artefactos (Pre-Acheulenses) foram encontrados no nível de terraço aos +110 a 120 m (com idade provável de 1,4 Ma) seria interessante promover trabalhos de prospeção arqueológica nos terraços T3, T2 e T1 do Baixo Tejo.

A projeção da elevação (a.r.b.) versus a idade da superfície de cada referência fluvial, permitiu estimar a idade dos depósitos do topo do T2 em ca. de $600 \mathrm{ka}$ e os do topo da unidade culminante do enchimento sedimentar em ca. de 1,8 Ma. Assim, estimou-se que a passagem da etapa de enchimento da bacia sedimentar para etapa de progressivo encaixe da rede hidrográfica se iniciou, provavelmente, há cerca de 1,8 Ma (transição Gelasiano Calabriano) e que a fase de agradação do terraço mais antigo do Baixo Tejo (T1) se terá iniciado há cerca de $1 \mathrm{Ma}$.

Calculou-se que para os últimos ca. $155 \mathrm{ka}$ as taxas de incisão de curto-termo apresentam valores $(0,09$ a $0,41 \mathrm{~m} / \mathrm{ka})$, aproximadamente, duplos dos calculados para o intervalo ca. 155 a $900 \mathrm{ka}(0,04$ a $0,28 \mathrm{~m} / \mathrm{ka}$ ). Relaciona-se este aumento da taxa de incisão com o aumento do soerguimento litosférico regional que se vem evidenciando por intensificação do contexto compressivo na margem SW Ibérica, pela interação entre a microplaca Ibérica e a placa Africana.

\section{AGRADECIMENTOS}

Este trabalho, sobre a evolução do rio Tejo em Portugal, pretende constituir uma Homenagem aos Professores A.M. Galopim de Carvalho, A. Brum Ferreira e João C. Pais A investigação nos terraços do Baixo Tejo tem vindo a ser desenvolvida com a colaboração de muitos colegas geólogos, geógrafos, arqueólogos e físicos, merecendo especial destaque: Martin Stokes, Jan-Pieter Buylaert, Andrew Murray, João Cabral, Luis Raposo, Pierluigi Rosina, Luiz Oosterbeek, Suzanne Daveau, Silvério Figueiredo, Jorge Dinis, Pedro Dinis, A. Alberto Gomes, João Caninas, Nelson Almeida, David Bridgland, J.P. Cunha Ribeiro e diversos investigadores da Associação de Estudos do Alto Tejo. Este estudo foi apoiado pela Fundação para a Ciência e a Tecnologia, através dos projectos UID/MAR/04292/2013 - MARE e UID/GEO/04683/2013 - ICT. Agradece-se aos colegas Diamantino Pereira, A. Alberto Gomes e Suzanne Daveau as revisões que efetuaram ao artigo e melhorias propostas.

\section{BIBLIOGRAFIA}

Almeida, N.; Deprez, S. \& De DApPer, M. 2008. The Palaeolithic occupation of the Northeastern of Alen Tagus (Portugal): a geoarchaeological approach. In: Bueno-Ramirez, P., Barroso-Bermejo, R., Balbín Berhmann, R. (Eds.), Graphical Markers and Megalith Builders in the International Tagus, Iberian Peninsula: British Archaeological Reports International Series, 1765, pp. 19-26. 
AzEVEDo, T. 1982. O Sinclinal de Albufeira, evolução pósmiocénica e reconstituição paleogeográfica. Tese de doutoramento, Univ. Lisboa, $302 \mathrm{p}$

BARBOSA, B.P. 1995. Alostratigrafia e litostratigrafia das unidades continentais da Bacia terciária do Baixo Tejo. Relações com o eustatismo e a tectónica. Tese de doutoramento, Univ. Lisboa, $253 \mathrm{p}$

BArbosA, B.P. \& REIS, R.P.B.P. 1996. Geometrias de enchimento, sistemas deposicionais e organização estratigráfica do Pliocénico continental da Bacia Terciária do Baixo Tejo (Portugal). Comun. Inst Geol. e Mineiro 82: 51-86.

Benito, G.; Sopena, A.; SAnchez-Moya, Y.; Machado, M.J. \& Perez-Gonzalez, A. 2003. Palaeoflood record of the Tagus River (Central Spain) during the Late Pleistocene and Holocene. Quaternary Science Reviews 22, 1737-1756.

Benito-Calvo, A.; Pérez-GonzÁlez, A. \& Santonja, M. 1998. Terrazas rocosas aluviales y travertínicas del valle alto del río Henares (Guadalajara, España) Geogaceta 24: 55-58

BENSAÚDE, A. 1910. Le tremblement de terre de la vallée du Tage du 23 avril 1909 (Note préliminaire). Bull. Soc. Port. Sc. Nat. III: 89-129.

Besana-Ostman, G.M.; Ferreira, H.; NArciso, J.; FaL CÃo Flor, A.P.; PINHEIRO, P.; NEMSER, E.; VILlANOVA, S.P. \& FonseCA, J.D. 2010. The Lower Tagus Valley Fault Zone: results of recent mapping activities. In: J.M. Insua and F. Martín González (eds.), First Iberian Meeting on Active Faults and Paleoseismology, Sigüenza (Guadalajara, Espanha): 37-40.

Besana-Ostman, G.M.; Villanova, S.P.; Nemser, E.S. FAlCão Flor, A.P.; HelenO, S.; Ferreira, H. \& FonSECA, J.D. 2012. Large Holocene Earthquakes in the Lower Tagus Valley Fault Zone, Central Portugal. Seismological Research Letters 83 (1): 67 -76, doi: 10.1785/gssrl.83.1.67.

Breuil, H. \& ZBYsZEWSKI, G. 1942. Contribution à l'étude des industries Paléolithiques du Portugal et de leurs rapports avec la géologie du Quaternaire. Les principaux gisements des deux rives de l'ancien estuaire du Tage. Comunicações dos Serviços Geológicos de Portugal XXIII, Lisboa, 369 p.

Breuil, H. \& ZByszewsKi, G. 1945. Contribution à l'étude des industries Paléolithiques du Portugal et de leurs rapports avec la géologie du Quaternaire. Les principaux gisements des plages quaternaires du littoral d'Estremadura et des terrasses fluviales de la basse vallée du Tage. Comunicações dos Serviços Geológicos de Portugal XXVI, Lisboa, $662 \mathrm{p}$

BRIDGLAND, D.R. 2000. River terrace systems in north-west Europe: an archive of environmental change, uplift and early human occupation. Quaternary Science Reviews 19: 1293-1303.

BRIDGLAND, D.R. \& MADDY, D. 2000. Global correlation of long Quaternary fluvial sequences: a review of baseline knowledge and possible methods and criteria for establishing a database. Netherlands Journal of Geosciences / Geologie en Mijnbouw 81 (3-4): 265-281.

BRIDGLAND, D.R. \& Westaway, R. 2008. Climatically controlled river terrace staircases: a worldwide Quaternary phenomenon. Geomorphology 98: 285-315.
Bridgland, D.R.; Antoine, P.; Limondin-Lozouet, N. Santisteban, J.I.; Westaway, R. \& White, M.J. 2006. The Palaeolithic occupation of Europe as revealed by evidence from the rivers: data from IGCP 449. Journal of Quaternary Science 21: 437. 455.

BuLL, W. 1990. Stream-terrace genesis: implications for soil development. In P.L.K. Knuepfer and L.D. McFadden (Eds.). Soil and Landscape Evolution. Geomorphology 3: 351-367.

Burbank, W. \& ANDERSON, S. 2001. Tectonic Geomorphology. Blackwell Science, 274 pp.

Burbank, W.; Meigs, A. \& Brozovic, N. 1996. Interactions of growing folds and coeval depositional systems. Basin Research 8: 199-223.

Buylaert, J.P.; Murray, A.S.; ThOMSEn, K.J. \& JaIn, M. 2009. Testing the potential of an elevated temperature IRSL signal from K-feldspar. Radiation Measurements 44: 560-565.

BuYlaerT, J.-P.; JaIn, M.; MurRay, A.S.; ThOMSEN, K.J.; Thiel, C. \& SohbATI, R. 2012. A robust feldspar luminescence dating method for Middle and Late Pleistocene sediments. Boreas 41: 435-451.

CABral, J. 1993. Movimentos neotectónicos verticais em Portugal Continental. Tentativa de síntese. Resumos $3^{a}$ Reunião do Quaternário Ibérico, Coimbra, pp. 31-37.

CABral, J. 1995. Neotectónica de Portugal continental. Memórias do Instituto Geológico e Mineiro Portugal 31, $265 \mathrm{p}$.

CABral, J. 2012. Neotectonics of mainland Portugal: state of the art and future perspectives. Journal of Iberian Geology 38 (1): 71-84.

CABral, J. \& Ribeiro, A. 1989. Carta Neotectónica de Portugal Continental, Escala 1:1.000.000. Nota explicativa. Serv. Geol. Portugal, Lisboa, $10 \mathrm{p}$.

CABRAL, J.; DiAS, R.P. \& BRUM, A. 1984. Estudo de falhas afectando formações plio-quaternárias na zona da Fonte da Telha (Península de Setúbal). Comun. Serv. Geol. de Portugal 70 (1): 83-91.

Cabral, J.; Marques, F.; Figueiredo, P.; Simão, N. \& MAtiAS, L. 2003a. New data on the active surface faulting vs. landsliding controversy concerning the Vila Chã de Ourique site (Lower Tagus Valley). Ciências da Terra N. Esp. 5, VI Congresso Nacional de Geologia, Caparica, D10-D13 (CD-ROM)

Cabral, J.; Moniz, C.; Ribeiro, P.; Terrinha, P. \& MAtias, L. 2003b. Analysis of seismic reflection data as a tool for the seismotectonic assessment of a low activity intraplate basin - the Lower Tagus Valley (Portugal). Journal of Seismology 7: 431447. doi: 10.1023/B: JOSE.0000005722.23106.8d

Cabral, J.; Ribeiro, P.; Figueiredo, P.; Pimentel, N. \& Martins, A. 2004. The Azambuja fault: an active structure located in an intraplate basin with significant seismicity (Lower Tagus Valley, Portugal). Journal of Seismology 8: 347-362.

Cabral, J.; Carvalho, J.; Martins, A.; Cunha, P.P.; Figueiredo, P.; Moniz, C. \& Dias, R. 2008. Active tectonic structures in the Lower Tagus Valley (West Iberia). 4th TOPO-EUROPE Workshop (Abstracts), 5-8 October 2008, Madrid, 1 p 
Cabral, J.; Marques, F.; Figueiredo, P. \& Matias, L. 2011. Active surface faulting or landsliding in the Lower Tagus Valley (Portugal)? A solved controversy concerning the Vila Chã de Ourique site. Journal of Seismology 15: 215-234. doi:10.1007/ s10950-010-9221-8.

Cabral, J.; Moniz, C.; Batlló, J.; Figueiredo, P.; CARVALho, J.; Matias, L.; TeVes-Costa, P.; Dias, R. \& SIMÃO, N. 2013. The 1909 Benavente (Portugal) earthquake: search for the source. Natural Hazards 69 (2): 1211-1227. doi:10.1007/s11069-011-0062-8.

CACHÃO, M. A. 1990. Posicionamento biostratigráfico da jazida pliocénica de Carnide. Gaia 2, 11-16.

Carrilho, F.; Nunes, J.C. \& PenA, J.A. 2004. Catálogo Sísmico de Portugal Continental e Região Adjacente 1970-2000. In: Senos, L.M. (coord), Instituto de Meteorologia. Lisboa, 227 p.

Carvalho, A.M.G. \& Daveau, S. 1971. Le dépôt grossier de la Serra da Galega, Finisterra, VI (11): 125-130.

Carvalho, J.; Cabral, J.; Gonçalves, R.; Torres, L. \& MENDES-VICTOR, L. 2006. Geophysical methods applied to fault characterization and earthquake potential assessment in the Lower Tagus Valley, Portugal. Tectonophysics, 418: 277-297. doi: 10.1016/j.tecto. 2006.02.010.

Carvalho, J.; Rabeh, T.; Cabral, J.; Carrilho, F. \& MiRANDA, J.M. 2008. Geophysical characterization of the Ota-Vila Franca de Xira-Lisbon-Sesimbra fault zone, Portugal. Geophys. J. Int. 174: 567-584. doi: 10.1111/j.1365-246X.2008.03791.x.

Carvalho, J.; Rabeh, T.; Dias, R.; Dias, R.; Pinto, C.; Oliveira, T.; Cunha, T. \& Borges, J. 2014. Tectonic and neotectonic implications of a new basement map of the Lower Tagus Valley, Portugal. Tectonophysics 617: 88-100.

Carvalhido, R.P.; Pereira, D.I.; Cunha, P.P.; BuYlaert, J.-P. \& MURRAY, A.S. 2014. Characterization and dating of coastal deposits of NW Portugal (MinhoNeiva area): A record of climate, eustasy and crustal uplift during the Quaternary. Quaternary International 328-329: 94-106. http:// dx.doi.org/10.1016/j.quaint.2014.01.025

CARvalho, G.S. 1968. Contribuição para o conhecimento geológico da bacia Terciária do Tejo. Mem. Serv. Geol. Portugal 15, 210 p.

Carvalho, N.; Cunha, P.P.; Martins, A.A. \& Tavares A. 2006. Caracterização geológica e geomorfológica de Vila Velha de Ródão. Contribuição para o ordenamento e sustentabilidade municipal. Açafa 7 , 73 p. e Anexos (cartografia temática).

Choffat, P. 1907. Notice sur la Carte Hypsométrique du Portugal. Com. Serv. Geol. Portugal VII: 1-71.

Choffat, P. 1912. Le tremblement de terre du 23 avril 1909 dans le Ribatejo. Revista de Obras Públicas e Minas XLIII: $31-50$.

Choffat, P. \& Bensaúde, A. 1911. Études sur le Séisme du Ribatejo du 23 Avril de 1909. Comm. Serv. Geol. Portugal, Lisboa, $140 \mathrm{p}$.

Conde, L.N. 1983. Mapa de fracturas de Portugal, Memória descritiva, EDP, 118p., 4 mapas. (Relatório inédito)

CONDE, L.N. \& ANDRADE, R.S. 1976. Exemplos de aplicação geológica de imagens de teledetecção de Portu- gal. $1^{\circ}$ Seminário sobre Detecção Remota e sua aplicação ao Estudo de Recursos Naturais e às Actividades do Homem, Julho de 1976, Lisboa, doc. 18 , policopiado.

Corral, I. 1998a. Depositos Cuaternarios en el área de Constância-Barquinha-Entroncamento y la Rib. del Bezelga. In: Cruz, A.R., Oosterbeek, L., Reis, R.P. (Eds.), Arkeos 4, Quaternário e Pré-História do Alto Ribatejo (Portugal). CEIPHAR, pp. 59-144.

CORRAL, I. 1998b. Secciones com material arqueológico en estrato en las proximidades de Atalaia. In: Cruz, A.R., Oosterbeek, L., Reis, R.P. (Eds.), Arkeos 4, Quaternário e Pré-História do Alto Ribatejo (Portugal). CEIPHAR, pp. 227-250

CosTA, L.F. 1984. Os terraços fluviais do Tejo entre os rios Torto e Alviela, Notas Geomorfológicas. Dissertação de Mestrado, Centro de Estudos Geográficos, Fac. Letras de Lisboa, 154 p.

CunHA, P.P. 1992a. Estratigrafia e sedimentologia dos depósitos do Cretácico Superior e Terciário de Portugal Central, a leste de Coimbra. Tese de Doutoramento, Universidade de Coimbra, 262 p

CunHA, P.P. 1992b. Establishment of unconformitybounded sequences in the Cenozoic record of the western Iberian margin and syntesis of the tectonic and sedimentary evolution in central Portugal during Neogene. First Congress R.C.A.N.S. - "Atlantic General Events During Neogene” (Abstracts), Lisboa, pp. 33-35.

CunHA, P.P. 1996. Unidades litostratigráficas do Terciário da Beira Baixa (Portugal). Comum. Inst. Geol. e Mineiro 82: 87-130.

CUNHA, P.P. 2000. Paleoalterações e cimentações nos depósitos continentais terciários de Portugal central: importância na interpretação de processos antigos. Ciências da Terra (UNL) 14: 145-154.

CUnHA, P.P. 2008. Papel desempeñado por la tectónica, el clima y el eustatismo en la génesis de los depósitos de Raña al pie de la Cordillera Central Portuguesa (Iberia occidental). Actas del VII Congreso Geológico de España, La Palma de Gran Canária, GeoTemas 10: 1507-1510, ISSN: 1567-5172.

CunHA, P.P. 2010. Importância da datação por luminescência em estudos de Geomorfologia e de Geologia do Quaternário. Actas do V Congresso Nacional da Geomorfologia Portuguesa, 8-11 de Dezembro de 2010, Univ. Porto, organizado pela Associação Portuguesa de Geomorfólogos, pp. 1-6. E-book (ISBN: 978-989-96462-2-3), http:// www.apgeom.pt/Activid/e-book.pdf

Cunha, P.P. \& MARTins, A.A. 2000a. Património geológico e geomorfológico da área de Vila Velha de Ródão. Estudos do Quaternário, Revista da Associação Portuguesa para o Estudo do Quaternário 3, APEQ, Lisboa: 91-104.

Cunha, P.P. \& Martins, A.A. 2000b. Transição do enchimento terciário para o encaixe fluvial quaternário na área de Vila Velha de Rodão (sector NE da Bacia do Baixo Tejo). Ciências da Terra 14: 171-182.

Cunha, P.P. \& Martins, A.A. 2004. Principais aspectos geomorfológicos de Portugal central, sua relação com o registo sedimentar e a importância do controlo tectónico. In: Geomorfologia do NW da Península Ibérica. M.A. Araújo \& A. Gomes (Editores), 
Faculdade de Letras da Universidade do Porto, pp. 155-178. ISBN: 972-8888-00-7.

Cunha, P.P. Proença; Barbosa, B. P. \& Pena dos Reis, R. 1993. Synthesis of the Piacenzian onshore record, between the Aveiro and Setúbal parallels (Western Portuguese margin), Ciências da Terra 12: 35-43.

Cunha, P.P.; Martins, A.A.; Daveau, S. \& Friend, P. 2005. Tectonic control of the Tejo river fluvial incision during the late Cenozoic, in Ródão - central Portugal (Atlantic Iberian border). Geomorphology 64: 271-298. doi: 10.1016/ j.geomorph.2004.07.004

Cunha, P.P.; Martins, A.; Huot, S.; Murray, A. \& RaPOSO, L. 2008a. Dating the Tejo river lower terraces in the Ródão area (Portugal) to assess the role of tectonics and uplift. Geomorphology 102: 43-54.

Cunha, P.P.; Dinis, P.; Martins, A.; Stokes, M. \& HandCOK, G. 2008b. Discussion of eustatic, climatic and tectonic controls on the Tejo River terraces genesis, at Alvega-Chamusca (Portugal, western Iberia). Fluvial Archives Group Meeting (Abstract Book), Budapest, Hungary, p. 34

Cunha, P.P.; Martins, A. \& Pais, J. 2008c. O estudo do Cenozóico em Portugal: estado da arte e perspectivas futuras. In: A Terra: Conflitos e Ordem, Livro de Homenagem ao Prof. Ferreira Soares, Univ. de Coimbra, pp. 101-110.

Cunha, P.P.; Almeida, N.A.C.; Aubry, T.; Martins, A.A.; Murray, A.S.; Buylaert, J.-P.; Sohbati, R., RAPOSO, L. \& RochA, L. 2012. Records of human occupation from Pleistocene river terrace and aeolian sediments in the Arneiro depression (Lower Tejo River, central eastern Portugal). Geomorphology 165-166: 78-90.

Cunha, P.P., Dinis, P., Martins, A.A. \& Stokes, M. 2015. Sedimentary characterization of a succession of aeolian sands in the Tejo River lower valley - a record of environmental changes of western Iberia during the Late Pleistocene to Holocene. Progress in Quaternary archive studies in the Iberian Peninsula (Proceedings), Seville (Spain), 12-13 March 2015, pp. 64-65.

Cunha, P.P.; Martins, A.; Buylaert, J.-P.; Murray, A.S.; RAPoso, L.; MozzI, P. \& STOKES, M. in press. New data on the chronology of the Vale do Forno sedimentary sequence (Lower Tejo River terrace staircase) and its relevance as fluvial archive of the Middle Pleistocene in western Iberia. Quaternary Science Reviews, Special Issue - Fluvial Archives Group, JQSR-S-16-00232

Cunha-Ribeiro, J.P. 2011. A jazida Paleolítica de Castelo Velho (Riachos, Torres Novas). Novos elementos para o seu estudo: a indústria lítica do locus 2. Estudos do Quaternário 7: 5-17.

CUNHA-RIBEIRO, J.P. 2013. O Paleolítico Inferior na margem direita do rio Tejo, entre a ribeira da ponte da Pedra e a foz do Alviela. Arkeos 34: 45-70.

CURA, S. 2014. Tecnologia litica e comportamento humano no Pleistocénico Médio final do Alto Ribatejo. estudo da indústria lítica da Ribeira da Ponte da Pedra, Tese de doutoramento, Univ. de Trás-osMontes e Alto Douro, Vol. 1 - 331 p., Vol. 2 - 100 p.

Cutler, K.B.; Edwards, R.L.; TAYlor, F.W.; Cheng, H.;
AdKINS, J.; GalluP, C.D.; Cutler, P.M.; BurR, G.S. \& BLOOM, A.L. 2003. Rapid sea-level fall and deep-ocean temperature change since the last interglacial period. Earth Planet. Sci. Lett. 206: 253-271.

Daveau, S. 1980. Espaço e Tempo. Evolução do ambiente geográfico de Portugal ao longo dos tempos préhistóricos, Clio, 2, 13 -37.

DAVEAU, S. 1985. Critères géomorphologiques de déformations tectoniques récentes dans les montagnes de schistes de la Cordilheira Central (Portugal), Bulletin de l'AFEQ, 24 (4): 229-238.

Daveau, S. 1993. Terraços fluviais e litorais, O Quaternário em Portugal. Balanço e Perspectivas, Associação Portuguesa para o Estudo do Quaternário, Colibri, 17-28.

DAVEAU, S. \& GonÇALVES, V. 1985. A evolução holocénica do Vale do Sorraia e as particularidades da sua antropização (Neolítico e Calcolítico), Actas I Reunião do Quaternário Ibérico, II: 187-197.

DeMets, C.; Gordon, R.G.; Argus, D.F. \& Stein, S. 1994. Effect of recent revisions to the geomagnetic reversal timescale. Geophysical Research Letters 21: 2191-2194.

DeMets, C.; Gordon, R.G. \& Argus, D.F. 2010. Geologically current plate motions. Geophys. J. Int 181: 1-80.

De Vicente, G.; Cloetingh, S.; Van Wees, J.D. \& CUNHA, P.P. 2011. Tectonic classification of Cenozoic Iberian foreland basins. Tectonophysics 502 (12): 38-61. doi:10.1016/j.tecto.2011.02.007

DiAs, R.P. \& CABRAL, J. 1989. Neogene and Quaternary reactivation of the Ponsul fault in Portugal. Comun Serv. Geol. Portugal 75: 3-28.

Dineva, S.; Batlló, J.; Mihailov, J.D. \& VAN EcK, T. 2002. Source parameters of four strong earthquakes in Bulgaria and Portugal at the beginning of the 20th century. Journal of Seismololgy 6: 99-123.

DINIS, J.O.F. 1910. Contribuição para o estudo dos tremores de Terra em Portugal: o abalo sísmico de 23 de Abril de 1909. Sep. da Revista de Obras Públicas 483 e 484, Imprensa Nacional, Lisboa, 59 p.

Diniz, F. \& MÖRner, N.-A. 1995. The Reuverian / Pretiglian transition in Rio Maior, Portugal. XIV Inter national Congress INQUA, Schriften der AlfredWegner-Stiftung 2/95: 64.

EsCUDERO, B. \& OLMO, D. 1997. Resultados paleomagnéticos de la raña del Hespérico Meridional (Montoro, Córdoba). Geogaceta 21: 31-34.

FLOR, G. 1999. Influencia fluvial en la sedimentación costeira. Encontros de Geomorfologia, Conferências. Universidade de Coimbra, pp. 59-94.

FREIRE DE ANDRADE, C.B. 1933. A tectónica do estuário do Tejo e dos vales submarinos ao largo da costa da Caparica, e a sua relação com as nascentes termomedicinais de Lisboa. Com. Serv. Geol. Portugal 19, 23-40.

FREIRE DE ANDRADE, C.B. 1937. Os vales submarinos portugueses e o diastrofismo das Berlengas e da Estremadura. Mem. Serv. Geol. de Portugal 7: 249 p

Gomes, H.; CunhA, P.P.; RosinA, P. \& OOSTERBEeK, L. 2012. Interpretation of clay mineral associations of Quaternary sediments at Alto Ribatejo (central Portugal). Estudos Arqueológicos de Oeiras 19: 223-230. 
HANCOK; G.S. \& ANDERSON, R.S. 2002. Numerical modeling of fluvial strath-terrace formation in response to oscillating climate. GSA Bulletin 114 (9): 1131 1142 .

JOANNES-BOYAU, R. 2014. Electron Spin Resonance (ESR) Dating in Archaeology. In Encyclopedia of Global Archaeology, pp. 2352-2358. DOI: $10.1007 / 978-1-4419-0465-2 \_2447$

Justo, J. \& SALWA, C. 1198. The 1531 Lisbon Earthquake, BSSA 88 (2): 319-328.

Lamothe, M.; Auclair, M.; Hamzaoui, C. \& Huot, S. 2003. Towards a prediction of long-term anomalous fading of feldspar IRSL. Radiation Measurements 37, 493-498.

LANCASTER, R.R., 2005. Fluvial evolution of the Garonne River, France: integrating field data with numerical simulations. Ph.D. Thesis, Louisiana State University, $87 \mathrm{p}$.

LAurent, M.; FAlguéRes, C.; Bahai, J.J; Rouseau,L. \& LANOÉ, B.V.L. 1998. ESR dating of quartz extracted from Quaternary and Neogene sediments: method, potential and actual limits. Quaternary Geochronology 17: 1057-1062.

Legoinha, P., 2001. Biostratigrafia de foraminiferos do Miocénico de Portugal (Baixo Tejo e Algarve). Tese de doutoramento, Univ. Nova de Lisboa, 241 p.

LISIECKI, L.E. \& RAYMO, M.E. 2005. A PliocenePleistocene stack of globally distributed benthic $\delta 180$ records. Paleoceanography 20 (1): 1-17. Doi 10.1029/2004PA001071

LóPez-Recio, M.; Silva, P.G.; RoQuero, E.; Cunha, P.P.; Tapias, F.; Alcaraz-Castaño, M.; Baena, J.; Cuartero, F.; Morín, J.; Torres, T.; Ortiz, J.E.; Murray, A.S. \& BuYlaERT, J.P. 2015. Geocronología de los yacimientos achelenses de Pinedo y Cien Fanegas (Valle del Tajo) e implicaciones en la evolución fluvial en el entorno de Toledo (España). Estudios Geológicos 71 (1): 1-19. Doi: http:// dx.doi.org/10.3989/egeol.41816.340

MADDY, D. 1997. Uplift-driven valley incision and river terrace formation in southern England. Journal of Quaternary Science 12 (6): 539-545.

Maddy, D., Bridgland, D. \& Green, C. 2000. Crustal uplift in southern England: evidence from the river terrace records. Geomorphology 33: 167-181.

Martín, T.; Ruiz, B. \& Pérez GonzÁlez, A. 1995. Reconstrucción paleoclimática y paleoambiental durante el Pleistoceno Medio en el Valle del río Tajo: primeros datos polínicos. In: T. Aleixandre y Alfredo Pérez González (Eds), Reconstrucción de paleoambientes y cambios climáticos durante el Cuaternario. Monografias del Centro de Ciencias Medioambientales 3: 347-361.

MARTín-Serrano, A. 1991. La definición y el encajamiento de la red fluvial actual sobre el Macizo Hespérico en el marco de su geodinámica Alpina. Revista Sociedad Geológica de España 4: 337-351.

Martín-Velázquez, S.; De Vicente, G.; Gómez-Ortiz, D. \& ElORZA, F.J. 2016. Strength of the Iberian intraplate lithosphere: Cenozoic deformations and seismicity. Journal of Iberian Geology 42 (1): 3954 ht t p ://d x.doi.org/10.5209/ rev_JIGE.2016.v42.n1.50836
MARTINS, A.A. 1999. Caracterização morfotectónica e morfossedimentar da Bacia do Baixo Tejo (Pliocénico e Quaternário). Tese de Doutoramento, Univ. Évora.

Martins, A.A. \& CunHA, P.P. 2006a. Vantagens e limitações da luminescência opticamente estimulada na datação de terraços do rio Tejo, sua importância na determinação da taxa de incisão fluvial. VII Congresso Nacional de Geologia, Resumos II, Estremoz, Portugal, pp. 683-686.

Martins, A.A. \& Cunha, P.P. 2006b. Possibilidades de aplicação da luminescência opticamente estimulada (OSL) na datação de sedimentos do rio Tejo. Tagus Floods 06 Workshop, Resumos, Lisboa, Portugal, pp. 72-75.

Martins, A.A.; Cunha, P.P.; HuOt, S., Murray, A., BUYLAERT, J. \& STOKES, M. 2008a. Geomorphological correlation of the Tejo river terraces in the Gavião -Chamusca area (central Portugal) supported by luminescence dating. Fluvial Archives Group Meeting, Abstract Book, Budapest, Hungary, p. 33.

Martins, A.A.; Cunha, P.P.; Buylaert, J.-P.; Murray, A.S.; DINIS, P. \& STOKES, M. 2008b. Luminescence dating and geological significance of a Pleistocene river terrace staircase sequence in the ArripiadoChamusca area of the Lower Tejo river (western Iberia). $12^{\text {th }}$ International Conference on Luminescence and Electron Spin Resonance Dating, Peking Univ., China, Abstracts, p. 111.

Martins, A.A.; Cunha, P.P.; HuOt, S.; Murray, A.S.; BuYlaERT, J.-P.; STOKES, M. \& CABRAL, J. 2008c. Quantifying tectonic displacements, fluvial incision and uplift using fluvial terraces of the Tejo River in western Iberia. 4th TOPO-EUROPE Workshop (Abstracts), 5-8 October 2008, Madrid, 1 p.

Martins, A.A. \& Cunha, P.P. 2009. Terraços do rio Tejo em Portugal, sua importância na interpretação da evolução da paisagem e da ocupação humana. In: Arqueologia do Vale do Tejo, CPGP, Lisboa, pp. 163-176. ISBN: 978-989-96416-0-0.

Martins, A.A.; Cunha, P.P.; Matos, J. \& Guiomar, N. 2009a. Quantificação da incisão do rio Tejo no sector entre Gavião e Chamusca, usando os terraços fluviais como referências geomorfológicas. Publicações da Associação Portuguesa de Geomorfólogos VI: 83-86.

Martins, A.A.; Cunha, P.P.; HuOt, S.; Murray, A. \& BUYLAERT, J.-P. 2009b. Geomorphological correlation of the tectonically displaced Tejo river terraces (Gavião-Chamusca area, Portugal) supported by luminescence dating. Quaternary International 199: 75-91. doi:10.1016/j.quaint.2009.01.009.

Martins, A.A.; Cunha, P.P.; BuYlaert, J.-P.; HuOt, S Murray, A.S.; Dinis, P. \& STOKES, M. 2010a. KFeldspar IRSL dating of a Pleistocene river terrace staircase sequence of the Lower Tejo River (Portugal, western Iberia). Quaternary Geochronology 5 (2-3): 176-180. http://dx.doi.org/10.1016/ j.quageo.2009.06.004

Martins, A.A.; Cunha, P.P.; Rosina, P.; OOSTERBECK, L.; Cura, S.; Grimaldi, S.; Gomes, J.; BuYlaert, J.P.; Murray, A.S. \& Matos, J. 2010b. Geoarchaeology of Pleistocene open-air sites in the Vila Nova da Barquinha - Santa Cita area (Lower Tejo River basin, central Portugal). Proc. Geol. Assoc. 121 (2): 128-140, doi:10.1016/j.pgeola.2010.01.005 
Martins, A.A.; VIS, G.-J. \& CUNHA, P.P. (Editors). 2010c. Quaternary fluvial archives of the Tejo River. Field trip from the upstream incised to the aggrading fluvial-tidal domain. FLAG Biennial Meeting 2010, $52 \mathrm{p}$

Merritts, J.; Vicent, R. \& WoHL, E. 1994. Long river profiles, tectonism and eustasy: a guide to interpreting fluvial terraces. Journal of Geophysical Research 99 (B7): 14031-14050.

Montenegro De Andrade, M. 1944. Estudo polínico de algumas formações turfo-linhitosas portuguesas. Publicações do Museu e Laboratório de Mineralogia e Geologia da Faculdade de Ciências do Porto 37, 5-11.

Oosterbeck, L.; Grimaldi, S.; Rosina, P.; Cura, S.; Cunha, P.P. \& MARTins, A.A. 2010. The earliest Pleistocene archaeological sites in western Iberia: present evidences and research prospects. Quaternary International 223-224: 399-407, doi: 10.1016/ j.quaint.2010.01.024

Ortiz, J.E.; Torres, T.; Delgado, A.; Reyes, E. \& DiaZBAUTISTA, A. 2005. A review of the Tagus river tufa deposits (central Spain): age and palaeoenvironmental record. Quaternary Science Reviews 28: 947-963.

PAIS, J. 1981. Contribuição para o conhecimento da vegetação miocénica da parte ocidental da bacia do Tejo. PhD, Univ. Nova Lisboa, 328 p.

Pais, J.; Cunha, P.P.; Pereira, D.; Legoinha, P.; Dias, R.; Moura, D.; Brum da Silveira, A.; KullberG, J. C. \& GonzÁlez-Delgado, J.A. 2012. The Paleogene and Neogene of Western Iberia (Portugal). A Cenozoic record in the European Atlantic domain. SpringerBriefs in Earth Sciences, Springer, Series ID: 8897 , 1st Edition, 1 vol., 158 pages.

PAis, J.; Cunha, P.P.; Legoinha, P.; Dias, R.P.; PEREIRA, D. \& Ramos, A. 2013. Cenozóico das Bacias do Douro (sector ocidental), Mondego, Baixo Tejo e Alvalade. In: Dias, R.; Araújo, A.; Terrinha, P. \& Kullberg, J.C. (Eds), Geologia de Portugal, Escolar Editora. 2 vol., 1624 p., pp. 1251-1323. ISBN 978-972-592-364-1

PAnera, J.; Torres, T.; PÉreZ-GonZÁlez, A.; Ortiz, J.E.; Rubio-JarA, S. \& URIBElarReA, D. 2011. Geocronología de la Terraza Compleja de Arganda en el valle del río Jarama (Madrid, España). Estudios Geológicos 67 (2): 495-504.

PANera, J.; Rubio-Jara, S.; Yravedra, J.; HuguesAlexandre, B.; Sesé, C. \& PÉreZ-GonzÁlez, A. 2014. Manzanares Valley (Madrid, Spain): a good country for Proboscideans and Neanderthals. Quaternary International 326-327: 329-343.

Pederson, J.; Anders, M.; RitTenhour, T.; SharP, W.; Gosse, J.; KARLSTROM, K. 2006. Using fill terraces to understand incision rates and evolution of the Colorado River in eastern Grand Canyon, Arizona. Journal of Geophysical Research 111: 1-10.

Pereira, D.I.; Pereira, P.; Brilha, J. \& Cunha, P.P. 2015. The Iberian Massif Landscape and Fluvial Network in Portugal: a geoheritage inventory based on the scientific value. Proc. Geol. Assoc. 126 (2): 252265. Doi: 10.1016/j.pgeola.2015.01.003.

PÉrez-GonZÁlez, A. 1994. Depresión del Tajo. In: Gutiérrez Elorza, M. (Ed.), Geomorfología de España. Editorial Rueda, Madrid, 389-436.
PÉreZ-GonzÁlez, A.; Silva, P.G.; Roquero, E. \& GaL LARDO, J. 2004. Geomorfología fluvial y Edafología del Sector Meridional de la Cuenca de Madrid (Toledo-Madrid). In: Benito, G., Díez Herrero, A. (Eds.), Itinerarios Geomorfológicos por Castilla-La Mancha. SEG, Toledo, Spain, pp. 13-50.

PÉrez-GonzÁlez, A.; Rubio Jara, S.; PANERA, J. \& URIBELARREA, D. 2008. Geocronología de la sucesión arqueoestratigráfica de Los Estragales en la Terraza Compleja de Butarque (Valle del río Manzanares, Madrid). Geogaceta 45: 39-42.

PÉreZ-GonZÁlez, A.; Gallardo-MilláN, J.L.; UribelarREA DEl VAl, D.; PANerA, J. \& Rubio-Jara, S. 2013. La inversión Matuyama-Brunhes en la secuencia de terrazas del río Jarama entre Velilla de San Antonio y Altos de la Mejorada, al SE de Madrid (España). Estudios Geológicos 69(1): 35-46.

Ramos, A.; Cunha, P.P.; Cunha, L.; Gomes, A.; LoPes, F.C; Buylaert, J.-P. \& Murray, A.S. 2012. The River Mondego terraces at the Figueira da Foz coastal area (western central Portugal): geomorphological and sedimentological characterization of a terrace staircase affected by differential uplift and glacio-eustasy. Geomorphology 165-166: 107-123. DOI: 10.1016/j.geomorph.2012.03.037

RAPOSO, L. 1995. Ambientes, territórios y subsistência en e Paleolítico Médio de Portugal. Complutum 6, 57-77.

RAPOSO, L. \& CARDoso, J. 1998. O Sítio do Paleolítico Médio da Conceição (Alcochete). Centro de Estudos e Monitorização Ambiental, 74 p.

Ribeiro, A., CABral, J., Baptista, R., Matias, L. 1996 Stress pattern in Portugal mainland and the adjacent Atlantic region, West Iberia. Tectonics 15: 641-659.

Roquero, E.; Silva, P.G.; Zazo, C.; Goy, J.L. \& MASANA, J. 2015a. Soil evolution indices in fluvial terrace chronosequences of Central Spain (Tagus and Duero fluvial basins). Quaternary International 376: 101-113.

Roquero, E.; Silva, P.G.; LóPez Recio, M.; TAPIAS, F.; Cunha, P.P.; Morín, J.; Alcaraz-Castaño, M; Carrobles, J.; Murray, A.S. \& Buylaert, J.-P. 2015b Geocronología de las terrazas del Pleistoceno Medio y Superior del valle del río Tajo en Toledo. In: Una vision global del Cuaternario. El hombre como condicionante de processos geológicos (J.P. Galve, J.M. Azañon, J.V. Pérez Peña y P. Ruano, Eds.), pp. 8-12. XIV Reunión Nacional de Cuaternario (Granada, España, 30 Junio - 2 Julio 2015).

Roucoux, K.H.; DE Abreu, L.; Shackleton, N.J. \& TZEDAKIS, P.C. 2005. The response of NW Iberian vegetation to North Atlantic climate oscillations during the last 65 kyr. Quaternary Science Review 24: 1637-1653.

Roucoux, K.; Tzedakis, P.; De Abreu, L. \& Shackleton, N. 2006. Climate and vegetation changes 180,000 to 345,000 years ago recorded in a deep-sea core off Portugal. Earth and Planetary Science Letters 249: 307-325.

RosinA, P. 2002. Stratigraphie et géomorphologie des terrasses fluviatiles de la moyenne Vallée du Tage (Haut Ribatejo, Portugal). In: Cruz, A.R., Oosterbeek, L. (Eds.), Arkeos 13, Territórios, mobilidade e povoamento no Alto-Ribatejo. IV: Contextos macrolíticos. CEIPHAR, pp. 11-52. 
Rosina, P.; VoInchet, P.; BAhain, J.; CRISTOVÃo, J. \& FALGUÈRES, C. 2014. Dating the onset of Lower Tagus River terrace formation using electron spin resonance. Journal of Quaternary Science 29(2): 153-162.

Rubio-Jara, S.; Panera, J.; Rodríguez de Tembleque, J.; SANTONJA, M.\& PÉreZ-GonZÁlez, A. 2016. Large flake Acheulean in the middle of Tagus basin (Spain): Middle stretch of the river Tagus valley and lower stretches of the rivers Jarama and Manzanares valleys. Quaternary international, http:// dx.doi.org/10.1016/j.quaint.2015.12.023

SAlgueiro, E.; Voelker, A.H.L.; ABreu, L. DE; Abrantes, F., Meggers, H. \& Wefer, G. 2010. Temperature and productivity changes off the western Iberian margin during the last $150 \mathrm{ky}$. Quaternary Science Reviews 29 (5-6): 680-695

SAntonja, M. \& PÉrez-GonZÁlez, A. 2010. MidPleistocene Acheulian industrial complex in the Iberian Peninsula. Quaternary International 223. 224: $154-161$

Silva, C.M. 2001. Gastrópodes Pliocénicos Marinhos de Portugal. Sistemática, Paleoecologia, Paleobiologia, Paleobiogeografia. Dissertação de Doutoramento, Univ. Lisboa, 747 p

Silva, P.G.; López-Recio, M.; TAPias, F.; Roquero, E.; Morín, J.; Rus, I.; CARrasco, P.; RodríGuez PascuA, M.A. \& PÉRez-LóPeZ, R. 2013a. Stratigraphy of the Arriaga Palaeolithic settlements: Implications for the geomorphological evolution of the lower Manzanares River valley (Madrid, Spain). Geomorphology 196: 138-161.

Silva, P.G.; RoQuero, E.; LóPez-Recio, M.; Huertas, P.; TAPIAS, F. 2013b. Statistical Approach to the chronosequence of fluvial terraces in the Tagus and Duero basins (Central Spain). In R. Baena, J.J. Fernández, I. Guerrero (Eds): El Cuaternario Ibérico: Investigación en el Siglo XXI. VIII Reunión de Cuaternario Ibérico. AEQUA, Sevilla, Spain, 29-33.

Sohbati, R.; Murray, A.; Buylaert, J.-P.; Almeida, N \& CUNHA, P.P. 2012. Optically stimulated luminescence (OSL) dating of quartzite cobbles from the Tapada do Montinho archaeological site (eastcentral Portugal). Boreas 41 (3): 452-462. Doi: 10.1111/j.1502-3885.2012.00249.x.

Stich, D., Batlló, J., Macià, R., Teves-Costa, P. \& MoRALES, J. 2005. Moment tensor inversion with single-component historical seismograms: The 1909 Benavente (Portugal) and Lambesc (France) earthquakes. Geophys. J. Int. 162: 850-858, doi: 10.1111/j.1365-246X.2005.02680.x.

Teves-Costa, P. \& Batlló, J. 2011. The 23 April 1909 Benavente earthquake (Portugal): macroseismic field revision. Journal of Seismology 15 (1): 59-70, doi: 10.1007/s10950-010-9207-6.

Teves-Costa, P., Rio, I., Marreiros, C., Ribeiro, R. \& BoRGES, J.F. 1999. Source Parameters of old earthquakes: Semi-automatic digitalization of analog records and seismic moment assessment. Natural Hazards 19: 205-220.

Vilanova, S.P. 2003. Sismicidade e Perigosidade Sísmica do Vale Inferior do Tejo. $\mathrm{PhD}$ thesis, Instituto Superior Técnico, Lisboa, 259 p.
VILANOVA, S.P. \& FonsECA, J.F.B.D. 2004. Seismic hazard impact of the Lower Tagus Valley Fault Zone (SW Iberia). Journal of Seismology 8: 331-345

Stokes, M.; Cunha, P.P. \& Martins, A.A. 2012. Techniques for analysing river terrace sequences. Geomorphology 165-166: 1-6. Doi: 10.1016/ j.geomorph.2012.03.022

Thomsen, K.J.; MurRay, A.S.; JAIN, M. \& BøTterJENSEN, L. 2008. Laboratory fading rates of various luminescence signals from feldspar-rich sediment extracts. Radiation Measurements 43: 1474-1486.

VAN DER SchrieK, T.; PASSMORE, D.G.; RolÃo, J. \& SteVEnson, A.C. 2007. Estuarine-fluvial floodplain formation in the Holocene Lower Tagus valley (Central Portugal) and implications for Quaternary fluvial system evolution. Quaternary Science Reviews 26: 2937-2957.

VIS, G.-J. 2009. Fluvial and Marine sedimentation at a passive continental margin. The late Quaternary Tagus depositional system. $\mathrm{PhD}$ thesis, Vrije University, $244 \mathrm{p}$.

VIS, G.-J.; Kasse, C. \& VAndenberghe, J. 2008. Late Pleistocene and Holocene palaeogeography of the Lower Tagus Valley (Portugal): effects of relative sea level, valley morphology and sediment supply. Quaternary Science Reviews 27: 1682-1709.

Vis, G.-J.: Kasse, C.; Kroon, D.; VAndenberghe，J.; JunG, S.; LEBreiro, S.M.\& Rodrigues, T. 2016 Time-integrated 3D approach of late Quaternary sediment-depocenter migration in the Tagus depositional systems: From river valley to abyssal plain. Earth-Science Reviews 153: 192-211.

WALlingA, J. 2002. Optically stimulated luminescence dating of fluvial deposits: a review. Boreas 31(4) $303-322$. D O I : $10.1111 / \mathrm{j} .1502$ 3885.2002.tb01076.x

WinTLE, A.G. 1973. Anomalous fading of thermoluminescence in mineral samples. Nature 245(5421): 143 144, DOI 10.1038/245143a0.

Wintle, A.G. \& Murray, A.S. 2006. A review of quartz optically stimulated luminescence characteristics and their relevance in single-aliquot regeneration dating protocols. Radiation Measurements 41: 369 391.

YuAn, Z.; ChEn, J. \& ZHANG, H. 2011. Terrestrial in situ cosmogenic nuclides burial dating and its application in Geosciences. Seismology and Geology 33 (2): 480-489

ZBYSZEWSKI, G. 1943. La classification du Paléolithic ancien et la chronologie du Quaternaire de Portugal en 1942. Boletim da Sociedade Geológica de Portugal $2(2-3), 111 \mathrm{p}$.

ZBYSZEWSKI, G. 1946. Étude géologique de la region d'Alpiarça. Comunicações dos Serviços Geológicos de Portugal XXVII: 145-268.

ZByszewski, G. 1953. Carta Geológica de Portugal, Noticia Explicativa da folha 31-A Santarém, na escala 1:50000. Direcção Geral de Minas e Serviços Geológicos de Portugal, $16 \mathrm{p}$.

ZByszewski, G. 1957. Le Quaternaire du Portugal. Mem Serv. Geol. Portugal 3 (N.S.): 184 p. 